\title{
EL TALLER ALFARERO PÚNICO DE CALLE REAL 210-212. ESTUDIO DE LOS MATERIALES, CRONOLOGÍA Y APUNTES SOBRE LA ARQUITECTURA FORNÁCEA
}

\section{THE PUNIC POTTERY WORKSHOP FOUND AT CALLE REAL 210-212. STUDY OF THE FINDS, CHRONOLOGY AND NOTES ON KILN ARCHITECTURAL FEATURES}

\section{Antonio M. SAEZ ROMERO ${ }^{1 *}$ y María Luisa LAVADO FLORIDO ${ }^{2 * *}$}

\author{
${ }^{1}$ Universidad de Sevilla, Departamento de Prehistoria y Arqueología, Facultad de Geografía e Historia, \\ Calle Doña María de Padilla s/n, 41004, Sevilla \\ ${ }^{2}$ Arqueóloga \\ * Correo electrónico: asaez1@us.es \\ ** Correo electrónico: marialuisa_lavado@hotmail.com
}

\begin{abstract}
Resumen: La intervención arqueológica preventiva dirigida en el año 2009 por M.L. Lavado puso al descubierto la existencia de un horno cerámico púnico y diversas fosas y testares en el área central de la actual ciudad de San Fernando (Cádiz), en el territorio insular meridional de la antigua Gadir/Gades. Este trabajo presenta un avance de los resultados del estudio de los materiales (esencialmente cerámicos) recuperados en la intervención, centrando la atención en los descubiertos en el interior del horno sobre la parrilla. Además de una clasificación tipológica y cronológica de estos contextos inéditos, que permiten establecer interesantes conexiones con otros alfares y yacimientos de la bahía gaditana activos entre los siglos V-III a.C., el excepcional estado de conservación del horno permite plantear algunas reflexiones sobre sus rasgos arquitectónicos, típicos de época púnica tardía.
\end{abstract}

Palabras Clave: Ánfora, sellos, comercio, economía, Gadir, adobe, alfar.

\begin{abstract}
The salvage archaeological excavation conducted in 2009 by M.L. Lavado revealed the existence of a Punic ceramic kiln and various pits and middens in the central area of the present-day city of San Fernando (Cadiz), in the southern insular territory of ancient Gadir/Gades. This work presents the preliminary results of the study of the material culture (essentially ceramics), focusing on the finds recorded inside the kiln on the holed-floor. In addition to a typological and chronological classification of these unpublished contexts, which allows to establish interesting connections with other kiln areas and sites in the bay of Cadiz that were active between the 5th and 3rd centuries BC, the outstanding state of preservation of the kiln makes it possible to reflect on the typical features of kiln design of the Late Punic period.
\end{abstract}

Keywords: Amphora, stamps, commerce, economy, Gadir, mudbrick, kiln.

Sumario: 1. Introducción. 2. Resultados de la Actuación Preventiva. 2.1. Estratigrafía y estructuras documentadas. 2.2. Estudio de los materiales. 2.2.1. El relleno del laboratorio (UUEE 09-11). 2.2.2. Los materiales de la "Fosa de trabajo" (UE 03). 3. Discusión y conclusiones. 4. Agradecimientos. 5. Bibliografía.

\section{Introducción}

Desde hace ya varias décadas se vienen documentado en el solar que actualmente ocupa la ciudad de San Fernando un destacado número de testimonios arqueológicos vinculados a la existencia de un "barrio alfarero" activo en época púnica y tardopúnica ligado al patrón de explotación del territorio insular de Gadir. Esta infraestructura esencial del asentamiento prerromano gaditano ha sido ya objeto de numerosas publicaciones que han intentado sistematizar los datos respecto al patrón general de distribución y explotación de estas instalaciones artesanales (Sáez, 2008a, 2013), a estudiar la cuantificación de su producción (García y Sáez, 2018; Sáez y Moreno, 2017) y 
también dar a conocer en detalle casos significativos como los de Torre Alta (Muñoz y Frutos, 2006; Sáez Romero, 2008b), Camposoto (Clavaín y Sáez, 2003; Ramon et al., 2007), La Milagrosa (Bernal et al., 2003: 187-205), Calle Asteroides (Sáez et al.., 2014), Luis Milena (Bernal et al., 2011), Villa Maruja - Janer (Bernal et al., 2003: 47-101; Sáez y Belizón, 2018) o Pery Junquera (González et al., 2001), entre otros.

A esta destacada nómina de áreas alfareras se sumó inesperadamente un nuevo punto gracias a las labores de control arqueológico desarrolladas en el año 2009 con motivo de la instalación en pleno corazón de la ciudad del nuevo tranvía interurbano, en un céntrico tramo de la actual Calle Real isleña (Figura 1), fosilización aproximada del viario antiguo y medieval-moderno, un punto en el cual no existían referencias a hallazgos previos de esta cronología (Bernal et al., 2005). Los trabajos preventivos realizados con motivo de la construcción del tranvía interurbano Cádiz-Chiclana dieron como resultado el hallazgo en la confluencia de esta arteria principal y la pequeña calle Diputado Ciscar de un horno cerámico de tipología y cronología púnica. El estado de preservación de esta nueva estructura era excepcional, con una cámara de cocción o laboratorio de planta pseudo-circular parcialmente excavada en el subsuelo (con más de $1 \mathrm{~m}$ de altura conservada) y un corredor de acceso alargado. El elemento más significativo era sin embargo el excepcional estado de la parrilla, conservada casi íntegra, constituida por adobes plano-convexos dispuestos de una forma radial, con huecos rellenados también por adobe y argamasa y con numerosas toberas perfectamente definidas. Se trata del mejor ejemplo descubierto hasta el momento de estos hornos púnicos gadiritas, cuya actividad, como veremos, debió extenderse hasta finales del siglo III a.C. Asimismo, se excavaron en los alrededores del horno algunos vertederos dispersos, alterados en ocasiones por la intensa actividad antrópica contemporánea, que han aportado significativos contextos materiales (fundamentalmente cerámicos, con abundantes desechos de cocción) datados entre los siglos $\mathrm{V}$ y I a.C., sugiriendo una secuencia de uso de la zona continuada, similar a la detectada en muchos otros de los puntos citados al inicio del apartado.

Desde la finalización de la intervención apenas se han dado a conocer algunos breves avances de los resultados del estudio de la secuencia, de las estructuras y de los contextos materiales aso- ciados, por lo que este trabajo supone la primera publicación en profundidad de estos aspectos. Sobre los pormenores de la actuación a lo largo de la Calle Real, con una amplia exposición epidérmica de los importantes hallazgos registrados en diversos sectores de esta arteria, se ha publicado un trabajo específico (por lo que remitimos a sus páginas para una contextualización en el ámbito de la AAP de 2008-2009 en el área de San Fernando; Cf. Lavado, 2017). Respecto al horno púnico y al denominado "sector de Patio Cambiazo" (que es el que ahora nos ocupa) sólo se ha publicado una breve nota poco después de la finalización de los trabajos, en la cual se apuntaron algunas primeras impresiones sobre la estructura y su papel en el panorama general del modelo de asentamiento artesanal de la zona en época púnica (Lavado y Sáez, 2009). El estudio de los materiales se llevó a cabo durante los años 2009 y 2010 en el marco de desarrollo de la tesis doctoral de uno de los firmantes (Sáez, 2014), viendo así la luz en estas páginas una versión actualizada de los inéditos resultados. El artículo pretende, por tanto, aportar un examen detallado de la estructura fornácea y de sus referentes constructivos (paralelos locales y mediterráneos), clasificar y cuantificar los materiales ligados a su fase de actividad y a su amortización, y enmarcar ambas cuestiones cronológicamente, situando los momentos clave de evolución de este taller cerámico parcialmente excavado en la Calle Real 210-212.

\section{Resultados de la Actuación Preventiva}

Como ya se ha señalado en la introducción, la actuación arqueológica preventiva (AAP) realizada entre los días 29 de julio y 12 de agosto de 2009 permitió documentar un horno alfarero de época púnica y, en particular, excavar el contenido del relleno interior de la cámara de cocción y de diversos testares situados en sus inmediaciones (Lavado y Sáez, 2009). Las necesidades de reurbanización de casi todo el trazado de la vía principal de la ciudad estaban motivadas por la instalación de las traviesas del nuevo tranvía interurbano, que paralelamente conllevaba la renovación de todas los sistemas de conducciones de servicios, pluviales y colectores ubicados debajo de la Calle Real, los cuales conformaban una auténtica maraña compleja de reubicar. El control arqueológico de estas obras, integral para todo el tramo urbano isleño, tenía por objetivo determinar la posible existencia 

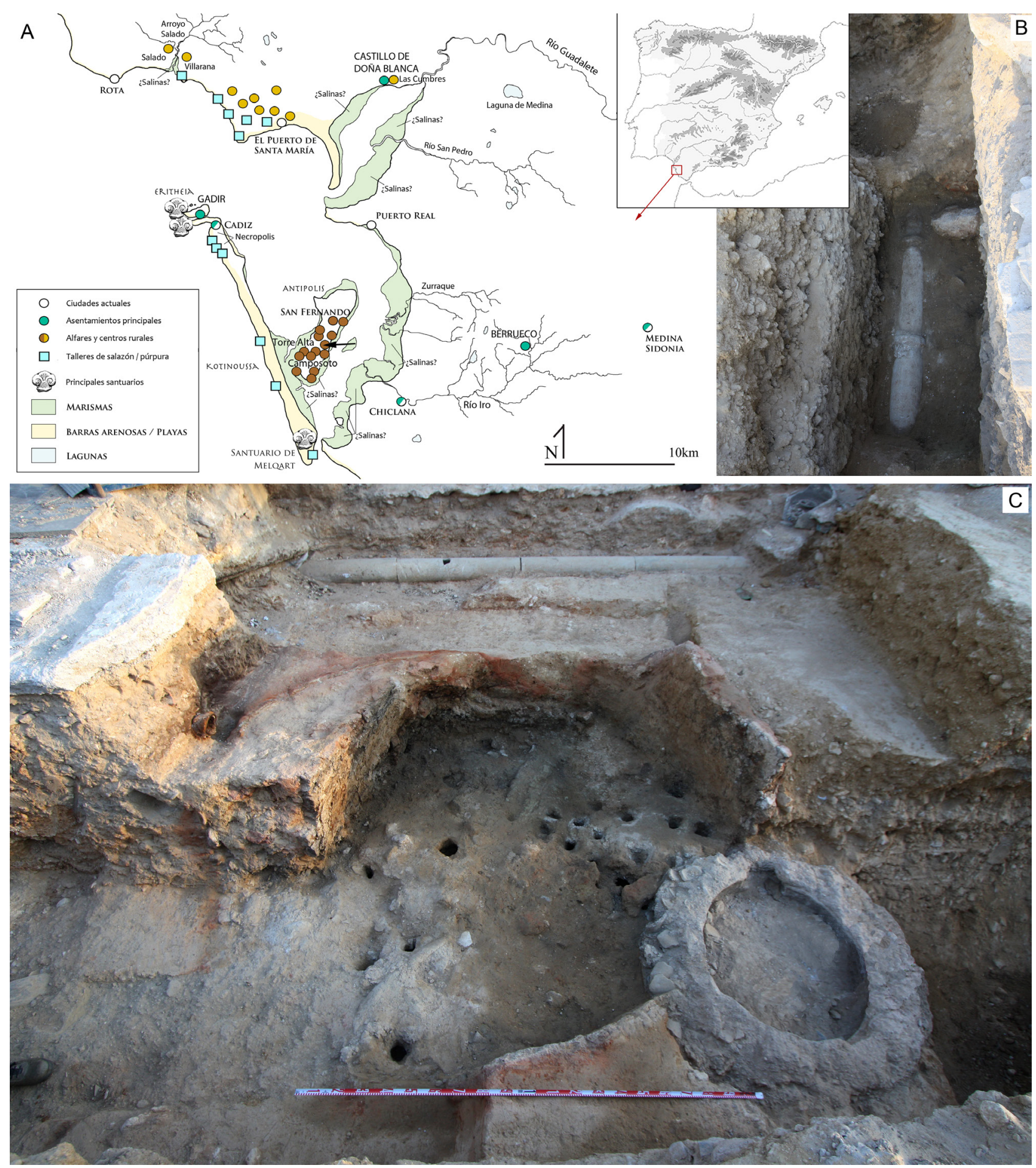

Figura 1. Plano de localización de los hallazgos de la Calle Real (a), y fotografías de la zona excavada: zanja y tubería contemporánea que motivó el descubrimiento del horno (b) y área de excavación intervenida en el año 2009 (c). La flecha indica la ubicación de Calle Real 210-212 en el mapa de distribución de los alfares insulares de Gadir. 
de restos en la anchura máxima de la calle hasta la cota máxima de afección (variable según las zonas y el tipo de conducciones afectadas). Mientras en las zonas laterales éstas eran abundantes, el tramo central de la vía registró mucha menor afección previa, necesitando asimismo con frecuencia de una cota menor de control (Lavado, 2017).

Esta área alfarera estuvo situada originalmente en la parte alta de la elevación que ascendía de forma suave desde la zona de Pery Junquera II (Bernal et al., 2005), Avda. Al-Andalus y El Canal (Sáez, 2008b: 462-466), estando situado en el inicio de la plataforma amesetada que conforma el punto central de la antigua isla, con un dominio visual pleno de toda la costa norte de la Antipolis estraboniana. La abundancia de talleres alfareros prerromanos y las evidencias cercanas de establecimientos rurales de época romana altoimperial hacen innecesario el buscar una explicación adicional a la elección de este punto para la instalación del complejo fabril, en una zona seguramente rica en recursos para el desarrollo de la actividad industrial (las estructuras se ubican directamente sobre el firme natural de margas amarillentas, explotables como materia prima arcillosa). A nivel más microespacial, la zona ocupada por el horno excavado en 2009 conforma un pequeño tell destacado del relieve situado más al norte, aspecto difícilmente perceptible actualmente dada la intensa urbanización sufrida por todo el entorno.

\subsection{Estratigrafía y estructuras documentadas}

En el caso del alfar púnico, los hallazgos se concentraron en un tramo de unos $100 \mathrm{~m}$ lineales situado aproximadamente a media distancia de los yacimientos de Batallones de Marina (Sáez, 2008b: 473-475) y Luis Milena (Bernal et al., 2011), algunos centenares de metros al sur de las localizaciones de El Canal y Torre Alta, en una zona en la que no se conocían previamente indicios de poblamiento antiguo (Figura 1a). Los trabajos comenzaron con la retirada por medios mecánicos del asfaltado y las capas de sub-base infrayacentes, bajo las cuales a la altura de la calle Diputado Ciscar se documentó una intensa concentración de conducciones de época contemporánea (fundamentalmente desagües y de aguas residuales) así como algunos pozos, lo que determinó la ejecución con una mayor lentitud de la retirada de estos elementos por medios mecánicos. En principio, la zona afectada por la obra se restringió a una zanja de unos 1,5 m de ancho paralela al acerado septentrional de la calle realizada por medios mecánicos que reactivaba otra anterior relacionada con una tubería de grandes dimensiones y un pozo ciego de hormigón.

La excavación en detalle de este punto de la zanja permitió documentar los primeros indicios de la estructura fornácea, así como la recuperación de algunas cerámicas dispersas que confirmaban la presencia de un yacimiento púnico en las inmediaciones. La estructura del horno se encontró parcialmente seccionada por varias de dichas conducciones, así como por el pozo, aunque en general podemos decir que el estado de conservación era excepcional, con la parrilla prácticamente íntegra y mostrando un alzado de las paredes de la cámara de cocción de en torno a $1 \mathrm{~m}$. La zanja anterior había cercenado aproximadamente la mitad meridional del alzado del laboratorio del horno (atravesándolo de lado a lado), pero la documentación de estas evidencias en su perfil permitió plantear la ampliación del área a excavar fuera de los propios límites del viario, conformando un cuadro de $3 \times 5 \mathrm{~m}$ inserto en el acerado de la calle y casi anexo a la valla de la parcela más próxima (número 210 de la Calle Real). Por tanto, además del trazado de la zanja abierta por la obra del tranvía, la excepcionalidad del hallazgo motivó la excavación de una amplia cuadrícula que cubría la práctica totalidad de la planta del horno alfarero (Figura 1c).

A pesar de la afección sufrida por el horno con la instalación de los tubos y el pozo, los trabajos efectuados en la zona acotada para la excavación revelaron el buen estado de conservación general, permitiendo la trinchera excavada para la adecuación de las nuevas conducciones ligadas al tranvía examinar una completa secuencia estratigráfica (Figura 2). La ampliación de la superficie en planta y este corte permitieron además examinar minuciosamente el sistema constructivo de la estructura (una correa perimetral de adobes cuadrangulares trabados con arcilla roja que forraban la fosa de la cámara) y la conservación in situ de gran parte del relleno original del laboratorio. De forma casi milagrosa, la zanja había profundizado hasta una cota inferior a los 1,40 m desde la rasante actual, lo que determinó que se conservase casi íntegramente la parrilla del horno. Este hecho, por el momento único ejemplo excepcional en el marco de los alfares púnicos de la península Ibérica, así como el hecho de quedar en parte fuera de la zona de afección de la obra, determinó la imposibilidad 
de excavar la cámara de combustión y otras áreas soterradas de la estructura, por lo que los trabajos se centraron en el relleno de la cámara de cocción. Paralelamente, a escasos metros al este del perímetro del horno se localizó en el perfil norte de la zona un vertedero de gran potencia totalmente colmatado con cerámicas y desechos de época púnica claramente vinculados al horno. Sin embargo, este depósito se extendía fuera de la zona afectada por la obra por debajo del acerado, por lo que no fue posible ampliar su excavación en dirección norte (hacia la finca de Calle Real 210).

El conjunto por tanto conformado por el vertedero y el horno se situó entre los puntos kilométricos (PPKK) 4+801/4+812, excavándose un tramo lineal de unos $12 \mathrm{~m}$ de longitud de la zanja a los que se añadió el cuadro de $3 \times 5 \mathrm{~m}$ planteado sobre el horno. Tras la retirada de las baldosas del acercado actual (UE 01a) y del nivel de zahorra de preparación del mismo, de unos $30 \mathrm{~cm}$ de potencia (UE 01b) en la zona a excavar se pudo comprobar la existencia de múltiples conducciones que habían afectado a los niveles de época antigua. Estas conducciones habían sido amortizadas por la UE 02 en la zona oriental de la zanja (constituida por sub-base con escasos ítems de cronología contemporánea) y por la UE 05 en la porción situada sobre el horno (tierra marrón revuelta con cerámicas moderno-contemporáneas).

Un vez retirados estos dos estratos en toda la superficie del área a excavar, se comprobó la presencia de un pozo (PZ-1) de aproximadamente $1 \mathrm{~m}$ de diámetro interior $(1,3 \mathrm{~m}$ si contamos el ancho de las paredes de hormigón), que parecía vinculado al vertido de aguas residuales y que conectaba originalmente con la gran tubería que había originado la excavación original de la zona (Figura 1b). La factura del pozo, así como su asociación al tubo mencionado, otorgan una datación contemporánea (¿mediados del siglo XX?) a la estructura y al sistema de conducciones asociado. Afortunadamente, aunque el pozo se había excavado sobre los adobes de la pared del horno y una pequeña fracción del interior, los daños ocasionados se restringían al cilindro de la estructura, cuya construcción no había revuelto el resto del relleno del horno. Otra pequeña zanja fue localizada en el área occidental del cuadro (UE 06), horadando en dirección norte-sur el firme geológico natural (margas amarillentas poco compactas, UE 04) y los adobes del recubrimiento perimetral del horno, lo que puso al descubierto la estructura. Otra zanja similar pero que no conservaba la tubería se cruzaba con la anterior cerca del ángulo NW del cuadro, afectando también al estrato geológico y a los adobes hasta casi rozar la pared del laboratorio (Figura 2: "tubo").

A pesar de todo, la estructura general del horno se encontraba en un estado de conservación notablemente mejor que en la mayor parte de casos anteriormente excavados en el área insular gadirita, permitiendo acercarnos a la estructura en planta y al proceso constructivo y de uso de la estructura fornácea. Éste puede resumirse en que tras excavar una fosa piriforme en la calcarenita y las margas de la base geológica, los artesanos forraron la fosa con un murete perimetral de aproximadamente $1 \mathrm{~m}$ de anchura realizado con adobes planos cuadrangulares trabados con arcilla roja (UE 08; Figura 2, recuadro), muy similares a los sistemas de conservación del calor documentados en los hornos tardoarcaicos de Camposoto (Ramon et al., 2007; Sáez, 2013: 224-231, fig. 4ij). Estos muretes fueron a su vez enfoscados con una capa de argamasa arcillosa rojiza, reparada constantemente durante sus diversas fases de actividad, quedando una huella indeleble del calor sufrido por esta parte de la estructura en la huella de rubefacción que se podía observar en el corte dejado por la zanja principal. En esta etapa probablemente se construiría el sistema de soporte de la parrilla originaria, aspectos ambos de los que no se pueden más que ofrecer conjeturas dado que no se pudo excavar el interior de la cámara de combustión.

La superficie interior del horno tenía una morfología levemente oval, con unas dimensiones máximas de 3,10 x 2,40 m, que lo aproximan a los hornos de mayores dimensiones documentados en Camposoto o Torre Alta, y por tanto a una relación fluida con la producción de ánforas y otros envases de gran porte. En la zona oeste del laboratorio pudo individualizarse una nueva unidad (UE 07) que estaba constituida por un murete realizado con arcilla rojiza, adobes rodados y fragmentos cerámicos, adosado a la pared inicial del laboratorio (Figura 3, arriba). Este añadido posterior presentaba también la costra arcillosa verdosa craquelada de las paredes del horno, siendo probablemente una reforma tardía realizada con el fin de reducir la superficie de la cámara de cocción del horno, indicando una prolongada actividad de la estructura o la existencia de dos fases diferenciadas (es decir, una segunda de reaprovechamiento 


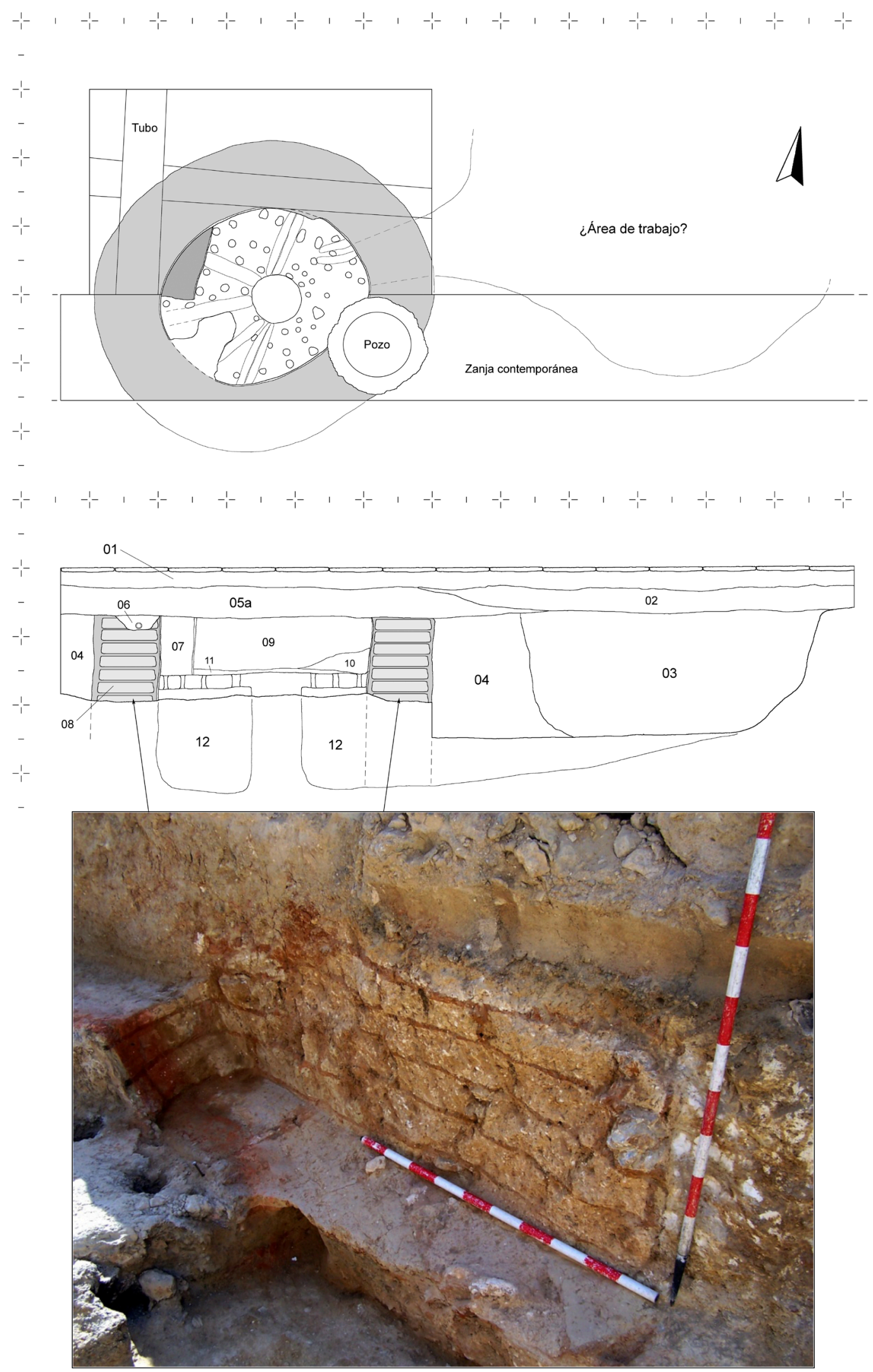

Figura 2. Planta y sección estratigráfica del horno y la "fosa de trabajo" obtenidas en la AAP del año 2009, con indicación de los contextos materiales analizados y restitución hipotética de la parte no excavada de las estructuras (cámara de combustión y corredor) [arriba]; Forro de adobes rectangulares parcialmente seccionado por la zanja contemporánea principal. En el corte se aprecia la disposición radial (con el lado corto hacia el laboratorio) de los adobes y la argamasa de arcilla rojiza utilizada para unirlos. 
y modificación de la estructura inicial). El alzado conservado de este adosado permitió además advertir que la reforma del interior del laboratorio conllevó el que sus paredes tuviesen una marcada inclinación hacia el centro de la estructura, dando la impresión de que dicha cámara superior cerraría no conformando un cilindro sino más bien una suerte de cúpula por aproximación de hiladas de adobes rectangulares. Estas modificaciones son aspectos que comienzan ahora a estar relativamente bien caracterizados en los hornos púnicos gaditanos y que se relacionan con la adopción de modelos fornáceos exógenos y la adaptación de las estructuras más antiguas para la producción de los tipos de ánforas propios de los siglos III-II a.C., más pequeños y acilindrados que los del $\mathrm{V}$ a.C. (una amplia reflexión y análisis de casos de estudio en García y Sáez, 2018).

La proximidad de las dimensiones y técnicas constructivas a los hornos tardoarcaicos documentados en Camposoto y Villa Maruja - Janer (estos últimos inéditos), así como la presencia en el relleno interior y en el vertedero anexo de materiales de dicha cronología, sugiere que la construcción de la primera versión del horno debió tener lugar cuando menos en el siglo V a.C. Parece probable por tanto que el pilar de sostén de la parrilla ligado a esta primera fase fuese de mayores dimensiones que la columna documentada en 2009, seguramente incluso formando un murete adosado a la pared trasera de la cámara de combustión como se ha podido ver en Camposoto. Precisamente el Horno 2 de este yacimiento proporciona un ejemplo estratigráficamente bien documentado de lo que pudo suceder con la estructura de la calle Real: quizá tras una etapa de desuso y amortización parcial, en algún momento del siglo III a.C. se decidió poner de nuevo en uso el horno, vaciando su interior, construyendo un nuevo pilar, adosando nuevos recubrimientos térmicos a las paredes (plaquetas) y modificando su planta hasta dotarlo de una cámara más circular y un corredor de alimentación más alargado (Sáez, 2008b: 447-452, 2013: 228-230). El relleno de arcillas y adobes fragmentarios construido en el interior de la cámara del horno de la Calle Real (UE 07) atestigua un proceso similar, aparentemente llevado a cabo con el objetivo de reducir las dimensiones (y capacidad) del laboratorio y dotarlo de una planta más circular, un diseño típico de hornos fechados en momentos avanzados del siglo III e inicios del II a.C. en la zona, como los hornos 1-2 de Torre
Alta (Muñoz y Frutos, 2006), con los cuales comparten además afinidades de detalle como el recubrimiento de argamasa arcillosa en la pared del laboratorio, la columna de adobes exenta y el uso de barras para la parrilla.

Sea como fuere, la parrilla documentada en la AAP del año 2009 se apoyaba sobre una columna circular exenta (de unos $70 \mathrm{~cm}$ de diámetro), ligeramente descentrada del eje del óvalo de la planta interior del horno. El suelo se conformó a partir del uso de un sistema de barras plano-convexas de adobe unidas por pares con argamasa arcillosa y dispuestas tanto radialmente a modo de vigas maestras como cruzadas (especialmente en el cuadrante noreste de la cámara) (Figura 3, abajo). Los huecos entre las barras se rellenaron con otros fragmentos de adobes más pequeños y argamasa arcillosa conformando un suelo regular perforado para el laboratorio, aunque las barras eran perfectamente visibles en su superficie. Numerosas toberas estaban dispuestas de forma irregular y sin una distribución estandarizada, aprovechando los huecos entre las barras principales, tanto junto a las paredes y la columna como en la parte central de la parrilla (Figura 4, arriba). En la zona occidental la apertura de la zanja había dañado parcialmente la parrilla, cayendo a la cámara de combustión algunos fragmentos.

Aunque contamos con varios casos más que conservaron parcialmente la parrilla en los talleres gadiritas, se trata sin duda del ejemplo en un estado más notable, sumando nuevos datos a un sistema de suspensión del piano forato o suola que abre interesantes perspectivas respecto de la evolución de la arquitectura fornácea local y de la interpretación de modelos foráneos a lo largo de los siglos III-II a.C. Como ya se apuntó en trabajos anteriores (Bernal et al., 2004; Sáez, 2008b: 194-205), se trata de un sistema que parece tener origen oriental, ya documentado en Levante en el Bronce Antiguo, y que cuenta con ejemplos destacados en los talleres cerámicos de Mozia (Cuomo di Caprio, 1978) y de la propia Cartago helenística (Falsone, 1981: 40-42), con cronologías que oscilan entre los siglos VI y II a.C. En el territorio de Gadir los ejemplos documentados refieren siempre a hornos pertenecientes a la facies artesanal de los siglos III-II a.C., como en Torre Alta, Pery Junquera, Asteroides o La Milagrosa, por citar sólo los ejemplos estratigráficamente más sólidos. Está ausente este sistema de barras de los hornos tardoarcaicos de Camposoto, donde las parrillas parecen estar fa- 

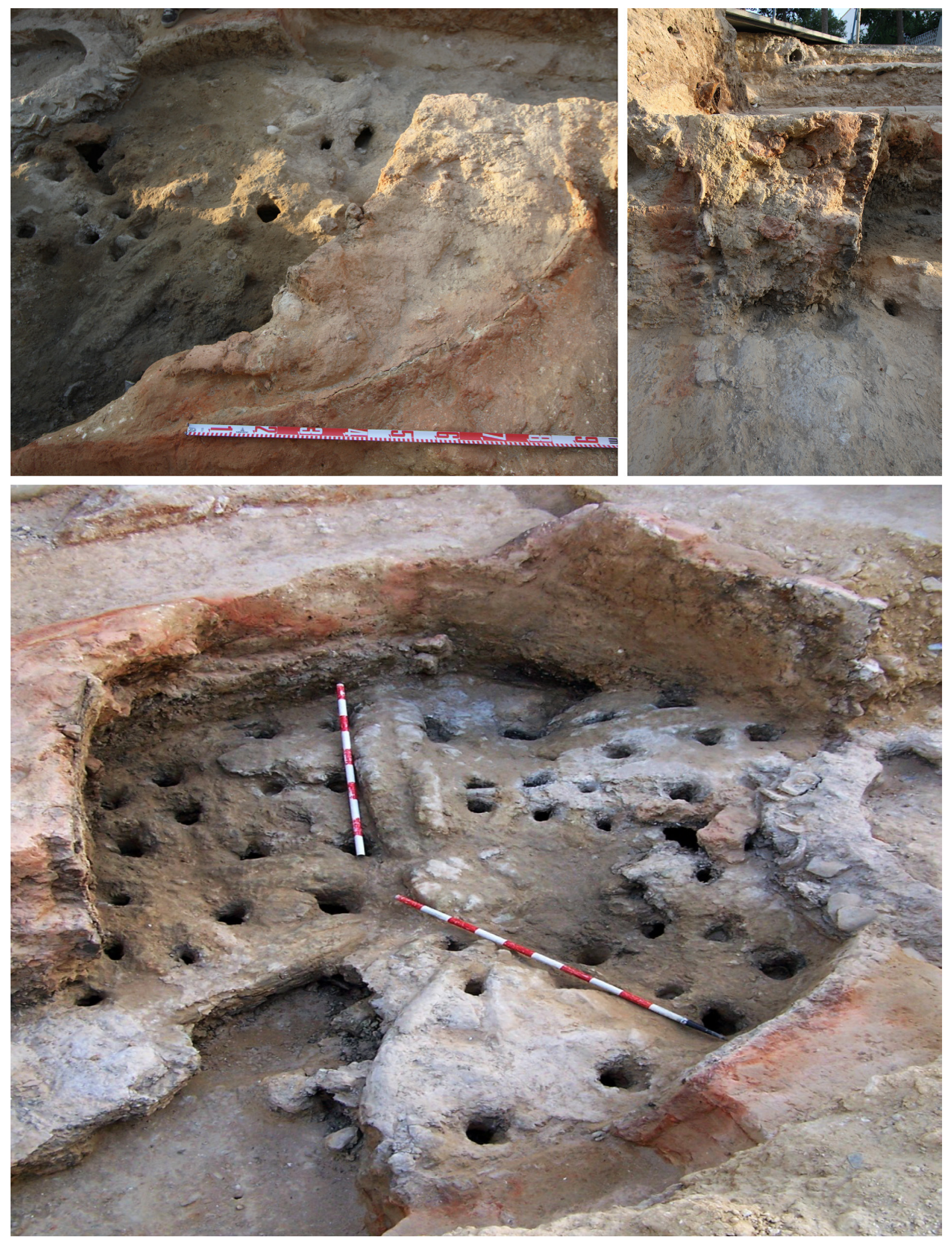

Figura 3. Vistas en planta (izq.) y en sección de la UE 07, añadido de arcilla con fragmentos de adobes que se empleó para reducir el tamaño del laboratorio (arriba); en el corte dejado por la zanja contemporánea de aprecian las dos fases de uso y sus correspondientes paredes rubefactadas. Abajo, vista desde el suroeste del laboratorio y la parrilla del horno de la calle Real, en la cual se aprecian tanto la morfología de las paredes (en su versión tardopúnica) como las barras de adobe empleadas en la construcción de la parrilla (según Lavado, 2017). 
bricadas conformando una gruesa placa de arcilla sobre formero lígneo, y tampoco se documentan indicios de estas barras en vertederos de los siglos V-IV a.C. como los examinados en Villa Maruja (Bernal et al., 2003), lo que apunta a que la adopción de este sistema corresponde a una modificación de los patrones de construcción de los hornos cerámicos locales operada en el curso del siglo III a.C., momento en el cual podemos situar la reforma del horno de la Calle Real (supuesto que encaja con los ítems vinculados a sus niveles de amortización; vide infra).

La excavación del tramo oriental de la zanja permitió documentar además parte de un vertedero cerámico de grandes proporciones (UE 03; fig. 3), hasta casi alcanzar a $-2,5 \mathrm{~m}$ la cota inferior de dicho depósito, excavado en la calcarenita de la UE 04. Este depósito apenas había sido afectado por la zanja, cuyo alcance en origen en esta zona había sido muy superficial, por lo que su excavación parcial aportó una significativa cantidad de materiales mezclados en una matriz cenicienta propia de vertidos de limpieza de horno (presentaba gran similitud con los testares MC-I/MC-II de Torre Alta o el documentado en Campo del Gayro; Sáez, 2008b). Asimismo, este vertedero sólo se extendía en planta hasta aproximadamente la mitad de la zanja, desarrollándose con mayor amplitud hacia el norte (Figura 4, abajo izquierda).

Por todo ello, consideramos que probablemente no se tratase de una fosa aislada, sino que esta pequeña porción excavada formaría parte de la "fosa de trabajo" situada frente al corredor de entrada a la cámara de combustión del horno, zona semi-soterrada en la cual desarrollarían los trabajos de limpieza y alimentación, con analogías claras en las grandes fosas excavadas en los conjuntos de hornos de Camposoto (Ramon et al., 2007). Aunque no fue posible excavar dicha cámara dada la preservación integral de la parrilla y el limitado espacio de actuación, la posición de las barras de adobe precisamente en la zona oriental del horno apoya también la posibilidad de que el corredor se encontrase orientado en dirección noreste conectando con esta posible área de trabajo subterránea.

Finalmente, la cámara de cocción proporcionó una secuencia sencilla de relleno previa a su amortización definitiva, en la cual predominan las deposiciones de tierras arcillosas marrón-rojizas con un alto componente cerámico muy fragmentario. Un depósito que probablemente fue generado en un solo esfuerzo o en momentos sucesivos con escaso espacio temporal entre ellos (como parece ser nota dominante en los talleres cerámicos locales). A pesar de la relativa homogeneidad de la matriz de los estratos diferenciados en el interior del laboratorio, pudieron distinguirse tres momentos distintos (Figura 3): por un lado, la capa superior, que casi suponía la totalidad del relleno (UE 09), con una tonalidad más clara; un nivel de cenizas negruzco con numerosas cerámicas asociadas (UE 10), ubicado sobre todo sobre la mitad norte de la parrilla (Figura 4, abajo derecha); y un pequeño depósito de tierra marrón arcillosa también con un significativo número de cerámicas directamente depositado sobre los restos de la zona sur de la parrilla (UE 11). Junto a la porción excavada de los rellenos de la "fosa de trabajo" (UE 03), estos niveles proporcionan una instantánea material significativa que permite situar cronológicamente el momento de abandono definitivo del horno y aportar sugerentes indicios sobre su construcción y fases iniciales de uso.

\subsection{Estudio de los materiales}

\subsubsection{El relleno del laboratorio (UUEE 09-11)}

En el estrato superior de la colmatación interior del laboratorio del horno (UE 09) el material recuperado fue muy abundante, aspecto lógico si consideramos que dicha capa de unos $80 \mathrm{~cm}$ de potencia ocupaba gran parte del espacio no afectado por las conducciones contemporáneas. Se trata de un relleno que habría sellado la cámara de cocción del horno de forma definitiva.

Entre las ánforas locales destaca la presencia de algunos individuos de T-11210 (Figura 5: 1-4) y posiblemente T-12111 (Figura 5: 5-6), con labios triangulares propios de los siglos V-IV, lo que sugiere un carácter residual de estos fragmentos. Sin embargo, el tipo más representativo de esta serie en la UE 09 es el T-12111/2 (Figura 5: 7-10), que ya muestra en la mayoría de los ejemplares rasgos consolidados de su proceso evolutivo: espaldas rectas rematadas en un labio engrosado redondeado, acanalado al exterior, con un "cono superior" prácticamente cilíndrico, hombros con aristas muy apuntadas y asas más pequeñas que presen$\tan$ frecuentemente digitaciones en el arranque superior (Sáez, 2008b, 2019).

El tipo de contenedor de transporte mayoritario en el contexto es el T-8211, presente tanto en sus versiones antiguas propias del siglo IV a.C. (Fi- 

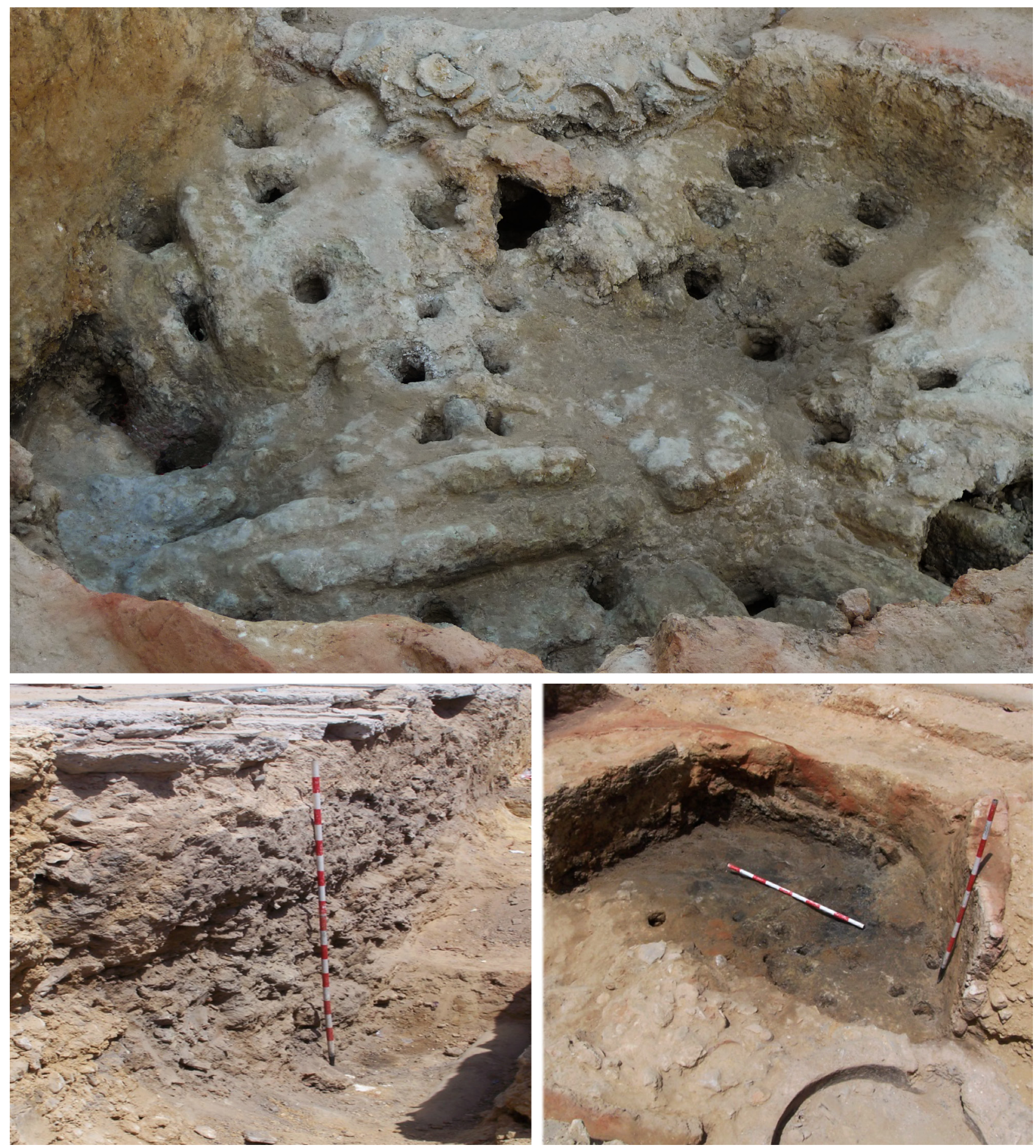

Figura 4. Detalle de la parrilla del horno y de las barras de adobe plano-convexas utilizadas en diversas posiciones para configurar el suelo y las toberas (arriba); Vertidos que colmataban la "fosa de trabajo" anexa al horno, parcialmente seccionados por la zanja contemporánea (según Lavado, 2017) [abajo, izquierda]. Proceso de excavación de las UUEE 10 y 11 del interior del laboratorio (abajo, derecha). 
gura 5: 12-13) como sobre todo en formas evolucionadas típicas de momentos avanzados del siglo III a.C. (Figura 5: 14-21). Mientras de la versión más antigua aparecen escasos individuos de labios cortos apenas diferenciados y pared con tendencia aún entrante, rasgos propios de un momento inicial de la forma, los individuos evolucionados del grupo T-8211 repiten de forma casi sistemática el mismo patrón formal simplificado: diámetro estrecho, paredes finas, bordes apenas engrosados y muy verticales, asas pequeñas, etc. El predominio en el contexto de los envases acilindrados se acentúa si consideramos la presencia de varios ejemplares de T-9111 (Figura 6: 1-7) de considerable diámetro, fondo rehundido similar al de las tinajas coetáneas y estructura de borde/pared muy similar al grupo anterior (aunque con menor desarrollo vertical). También se encuentran en el contexto algunas versiones locales de ánforas grecoitálicas antiguas (Figura. 6: 8-15) con labios triangulares no macizados, asas de sección aplanada y pivotes huecos desarrollados, que por tanto reproducen bastante fielmente los prototipos propios de avanzado el siglo III a.C. (una cuestión ampliamente tratada en Bernal et al., 2013; Sáez y Díaz, 2007).

Aunque el material de producción local es ampliamente mayoritario, entre las ánforas se documentan las escasas importaciones identificadas en el estrato: el 1/4 superior de una T-12111 de pasta marrón con abundante desgrasante de esquisto (Figura 5: 11) cuya tipología y pasta parecen apuntar a un origen tingitano mediterráneo o quizá en la costa malacitana; asimismo, también se recuperó un borde indiferenciado de envase del tipo Pellicer D (Figura 6: 16), abundantes en otros talleres en las fases tardopúnicas de la actividad (Sáez Romero, 2008b) y también en contextos de la segunda mitad del siglo III tanto de la necrópolis insular gadirita (Niveau de Villedary, 2009) como en el Castillo de Doña Blanca (Niveau de Villedary, 2002).

En lo referido a la vajilla barnizada de producción local registrada en el estrato (también llamada "de tipo Kuass"; Cf. Niveau y Sáez, 2016), podemos hacer una consideración similar sobre la coexistencia de elementos antiguos mezclados con otros de clara datación tardopúnica, dando cuenta de una significativa residualidad en el contexto. El tipo quizá mejor representado sea el de los platos de pescado L23, del que contamos con varios bordes con y sin acanaladura (Figura 6: 19-20) y una base con pie anular y estriado alrededor del po- cillo (Figura 6: 22). A platos precursores de estas versiones más evolucionadas parecen corresponder por el contrario otras dos bases de pie indicado, una de ellas con la cubierta casi perdida, con engobado sólo al interior (Figura 6: 21 y 34). El repertorio de formas abiertas se completa con una base de filiación indeterminada (¿plato Niveau I? Figura 6: 32) y un fragmento de pared y arranque del borde que habría que asociar a una interpretación local de páteras L36, aunque en una versión de menor talla (Figura 6: 33) bien caracterizada en contextos alfareros locales de finales del siglo III a.C. como el testar del Sector 1 de Torre Alta.

Entre los cuencos el fenómeno se repite, como observamos a partir de la presencia de formas hemiesféricas o de cuarto de esfera con engobe rojo al interior (Figura 6: 17-18), probablemente residuales. Éstos comparten estrato con producciones "de tipo Kuass" con cubierta total de barniz del tipo Niveau IX (fig. 10: 23) y versiones gadiritas de L27/Niveau X (Figura 6: 26). Asimismo, también pertenecientes a formas evolucionadas del repertorio helenístico local, encontramos varias copas Niveau VIII (Figura 6: 4-5) y un bolsal (Figura 6: 30 ), así como bases de formas no precisables (Figura 6: 29 y 31). Los elementos pintados en rojo se restringen a un cuenco con una estrecha banda sobre el borde (Figura 6: 25), quizá también residual, y a un ungüentario globular de la serie A de Muñoz (1987) que presenta una triple banda de pintura sobre la parte alta del cuerpo (Figura 6: 35). Aunque fabricadas en pastas comunes, el buen acabado exterior de otras dos piezas parece relacionarlas con el grupo de vajilla barnizada: se trata de un plato de borde triangular muy moldurado (Figura 6: 36), quizá una prueba del taller desechada, y de una versión local de small bowl o saltcellar (Figura 6: 37), ambos con engobados espesos de barbotina del color de la pasta y un cuidado alisado de las superficies.

El estrato también proporcionó un notable conjunto de cerámicas comunes sin tratamiento que constituían cuantitativamente el grueso del contexto, y entre las cuales de nuevo se detectan fenómenos de residualidad, aunque en su mayoría las formas se corresponden con el horizonte tipológico propio de la segunda mitad del siglo III o inicios del II a.C. (Sáez, 2008b: 622-664) Un primer subgrupo abundante es el formado por los cuencos hemiesféricos de gran tamaño y profundidad cercanos al tipo GDR-1.3.2/1.3.3 (Figura 7: 4) y en menor medida por versiones más reduci- 

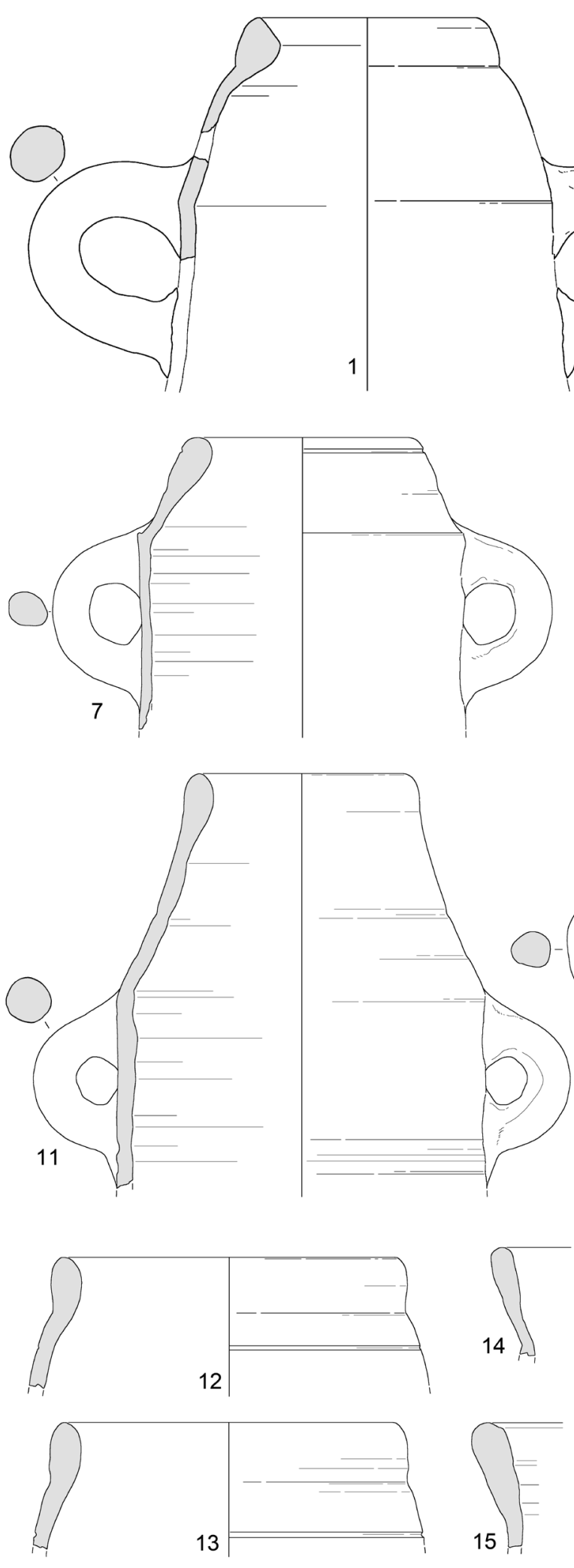
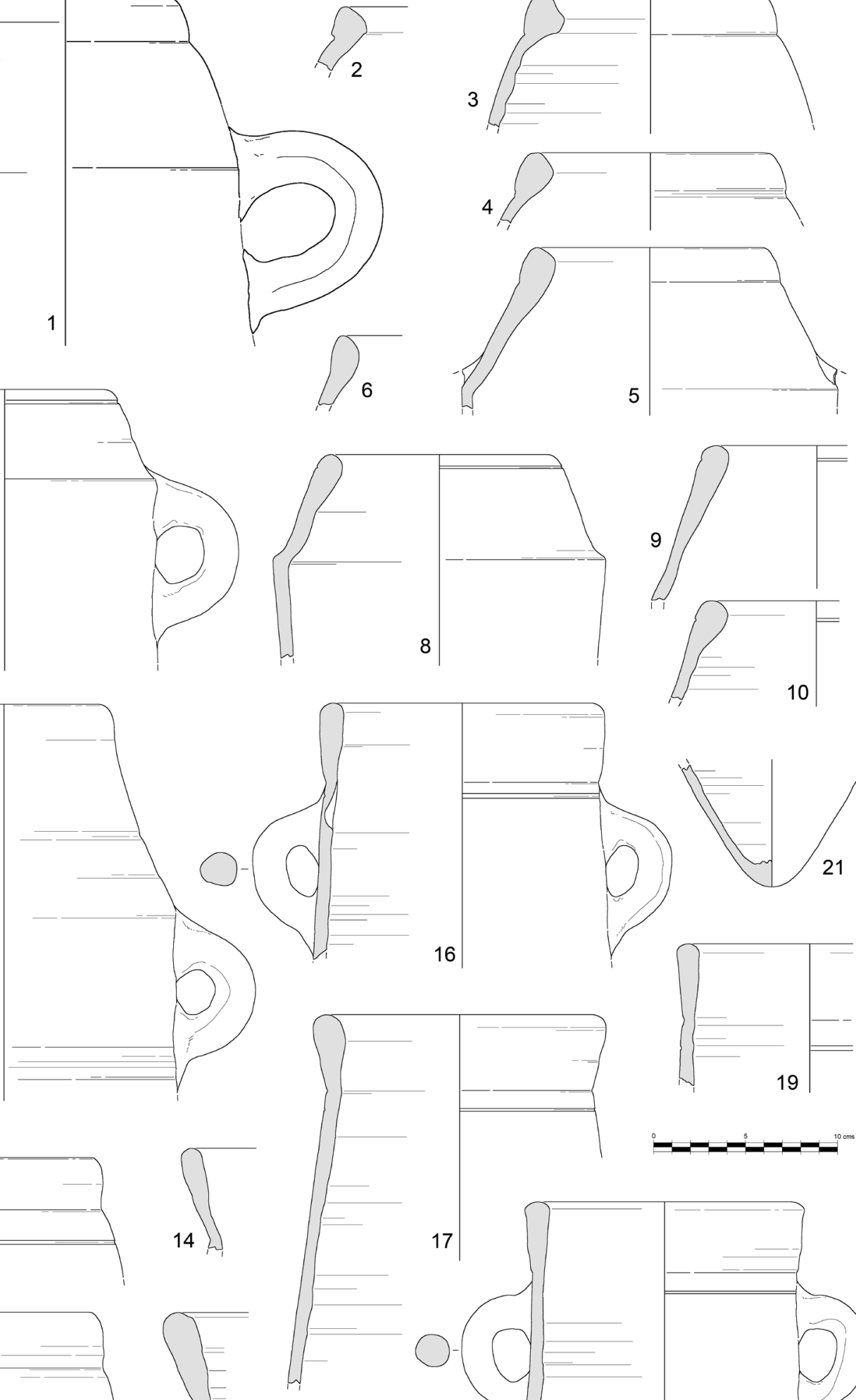

16
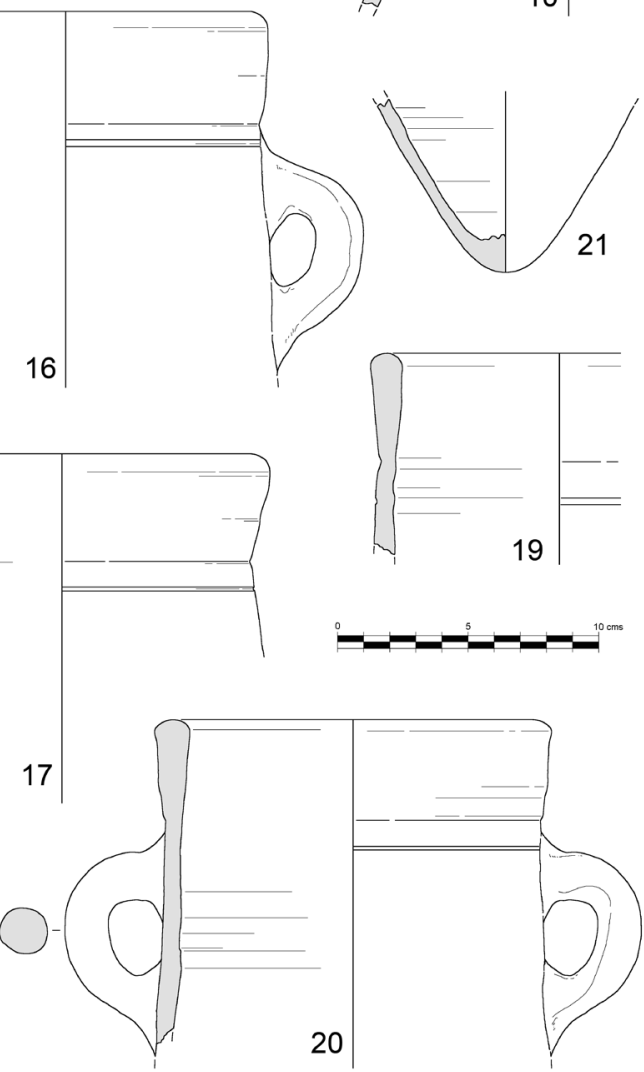

20

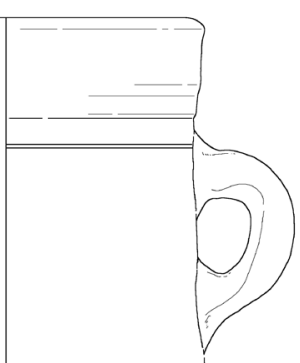

Figura 5. Materiales anfóricos documentados en la UE 09 de la cámara de cocción (Esc. 1:4). 

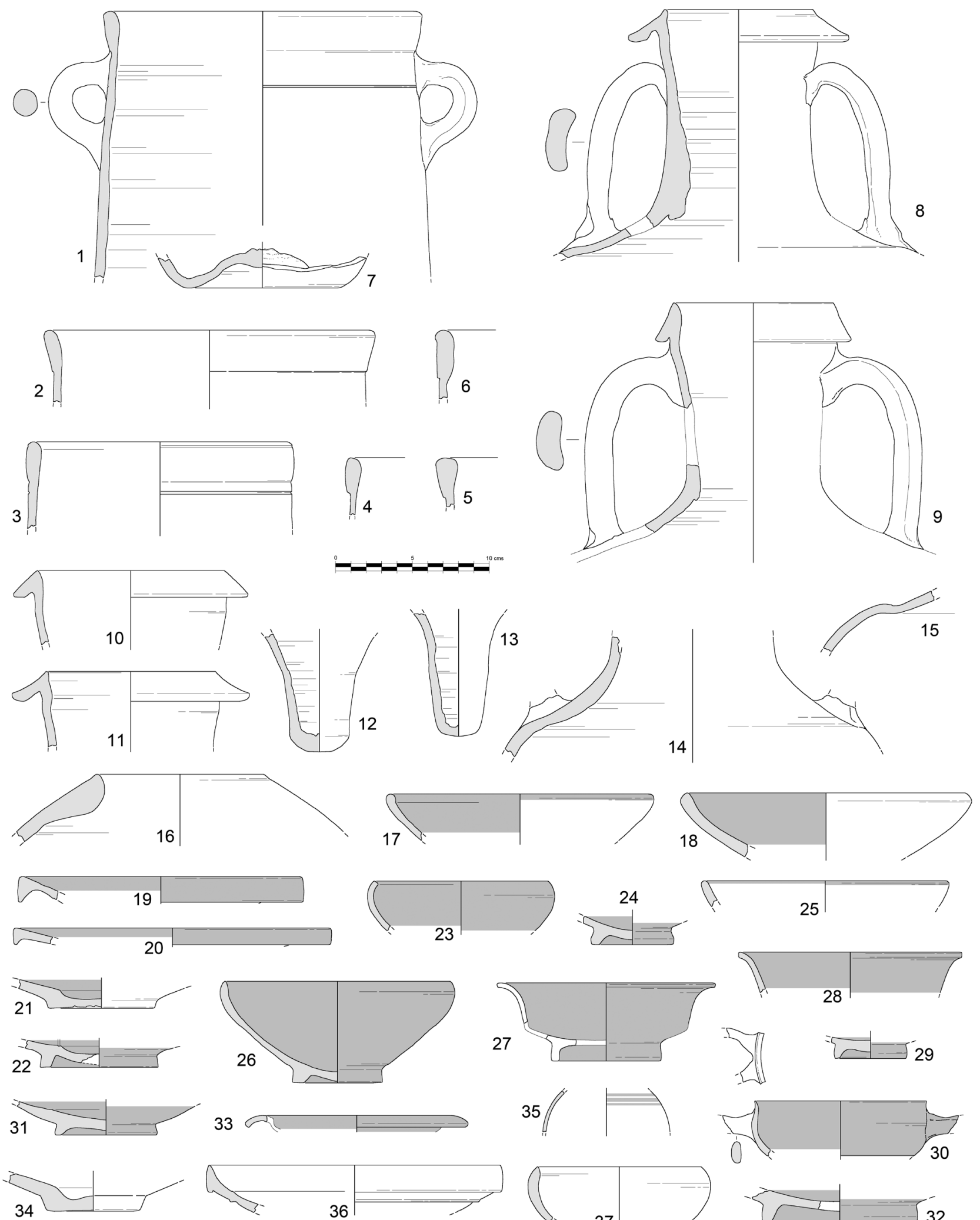
33
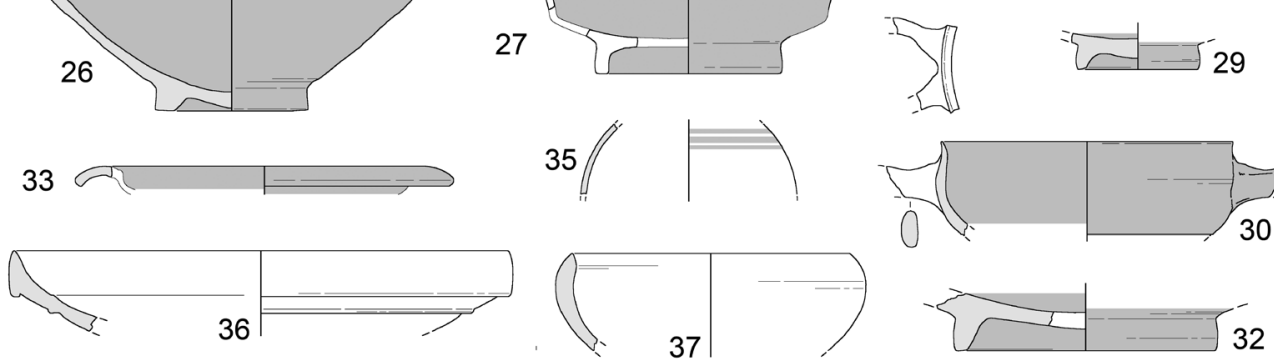

37

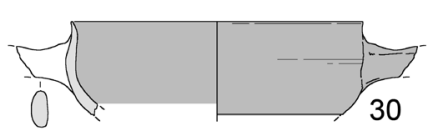

Figura 6. Ánforas locales (1-15), importada (16), vajilla de barniz rojo (17-33) y otras producciones locales de la UE 09 del interior del horno (Esc. 1:4).

Revista Atlántica-Mediterránea de Prehistoria y Arqueología Social 22, pp. 109-137

Universidad de Cádiz 
das pero igualmente profundas próximas al GDR1.2.1 (Figura 7: 1-3). No menos numerosas son las páteras carenadas del tipo GDR-2.1.0 (Figura 7: 7). Se trata en todos los casos de formas muy frecuentes en la necrópolis tardopúnica (Niveau de Villedary 2009), en Doña Blanca (Ruiz y Pérez, 1995) y en otros alfares con fases tardopúnicas (Sáez, 2008b). Destaca la presencia de versiones antiguas de estas páteras carenadas dotadas de labios notablemente moldurados (Figura 7: 5) o con la característica doble incisión (Figura 7: 6), versiones ambas documentadas significativamente en algunos contextos de Villa Maruja que se fechan en el siglo IV a.C. (Bernal et al., 2003).

Los platos-mortero del tipo GDR-3.2.0, con labios ligeramente colgantes y bases con estrías concéntricas (Figura 7: 9) también conforman un conjunto nutrido, advirtiéndose la presencia entre ellos de ejemplares de pequeño tamaño. El resto de formas abiertas de gran porte se reduce a unos pocos lebrillos (Figura 7: 10-11) con los clásicos bordes casi horizontales vueltos al exterior. Finalmente, debemos destacar la destacada proporción de vasos de perfil en $S$ hallados en el estrato, tanto de la variante de mayor tamaño GDR-7.2.0 (Figura 7: 12-13) como de tamaños más reducidos y variables relacionados con el GDR-7.1.0 (Figura 7: 14-16). Una copa carenada mucho más abierta, aunque emparentada con estos vasos, recuerda vivamente producciones precursoras atestiguadas en contextos de los siglos V-IV de Villa Maruja o Camposoto (Figura 7: 8).

En el apartado referido a las formas cerradas torneadas en pastas comunes locales cabe señalar que como suele ser habitual en estos horizontes tardopúnicos el panorama del estrato UE 09 aparece dominado por las tinajas sin asas del tipo GDR-8.1.1 (Figura 7: 24-28), mostrando la presencia tanto de individuos de talla normal como versiones reducidas. El resto de tipos del repertorio local está representado en números mucho más modestos, contándose apenas algunos ejemplares de jarritas tipo olpe GDR-10.2.0 (Figura 7: 20), jarritas piriformes del tipo GDR-10.4.1 (Figura 7: 21) o enocoes no tipificados quizá emparentados con estas últimas (Figura 7: 19).

Asimismo, destaca la presencia de varios ejemplares, uno de ellos bastante completo (Figura 7: 17-18), de tinajas del grupo GDR-12.2.2, probablemente versiones locales de prototipos cartagineses del tipo Cintas 224 o formas relacionadas (Cintas, 1950). El individuo más completo de la UE 09 permite apreciar que se trata de una jarra mediana biansada, de cuerpo casi globular rematado en un borde horizontal proyectado al exterior y apoyado sobre un pie ligeramente indicado destacado de un fondo rehundido similar al de otras tinajas locales; las asas horizontales serían de pequeño tamaño, colocadas casi a la altura del diámetro máximo, en contacto con una o más acanaladuras horizontales dispuestas al efecto. Como ya adelantamos para los hallazgos de Luis Milena (Bernal et al., 2011) o Torre Alta (Sáez et al., 2016), se trata de una forma ajena a la tradición local de muy probable influencia cartaginesa, posiblemente destinada al almacenaje doméstico a pequeña escala. Cerrando este grupo encontramos un borde de diámetro amplio y notablemente exvasado (Figura 7: 23) que podría corresponder a un elemento residual (jarra o tinaja sin asas derivada de los pithoi arcaicos), aunque no puede desecharse la posibilidad de que se trate de una tinajilla tardopúnica del tipo GDR-9.1.1. Un asa adosada a un fragmento de pared, casi un mamelón, completa el repertorio hallado en el estrato (Figura 7: 22), certificando la presencia de tinajas o grandes recipientes de paredes gruesas entre la producción de estos talleres.

La cerámica "de cocina" es también abundante en este nivel superior de la colmatación del laboratorio, documentándose de nuevo la presencia de algunos individuos presuntamente residuales pero predominando las variantes tardopúnicas más frecuentes (Sáez, 2018). Éstos se reducen a un par de ejemplares de ollas de tendencia globular con labios exvasados, una de ellas vinculada a la morfología de las DIVa1 de Camposoto (Figura 8: 1) y otra más próxima a posibles descendientes de las DIVb1 (Figura 12: 2). Otro grupo de ollas bien representado es el de las GDR-12.3.0 (Figura 8: 5-6), GDR-12.4.2 (Figura 8: 4 y 7) o quizá incluso GDR-12.5.1 (Figura 8: 3), con ejemplares de volúmenes medios o grandes. Sin embargo, el recipiente de cocina más abundante es la cazuela profunda del tipo GDR-11.3.0 (Figura 8: 8-15), que parece en origen iría acompañada por tapaderas simples quizá conformadas por platos/cuencos reversibles (Figura 8: 20). Un ejemplar de esta serie de pequeño tamaño, con intensas huellas de ennegrecido exterior derivadas de su uso prolongado, podría pertenecer al tipo GDR-11.3.3 (Figura 8: 16). No están ausentes tampoco las cazuelas de paredes exvasadas también dotadas de labios con solero cercanas al prototipo de las GDR-11.1.0 (Figura 8: 18-19), aunque en mucho menor número 

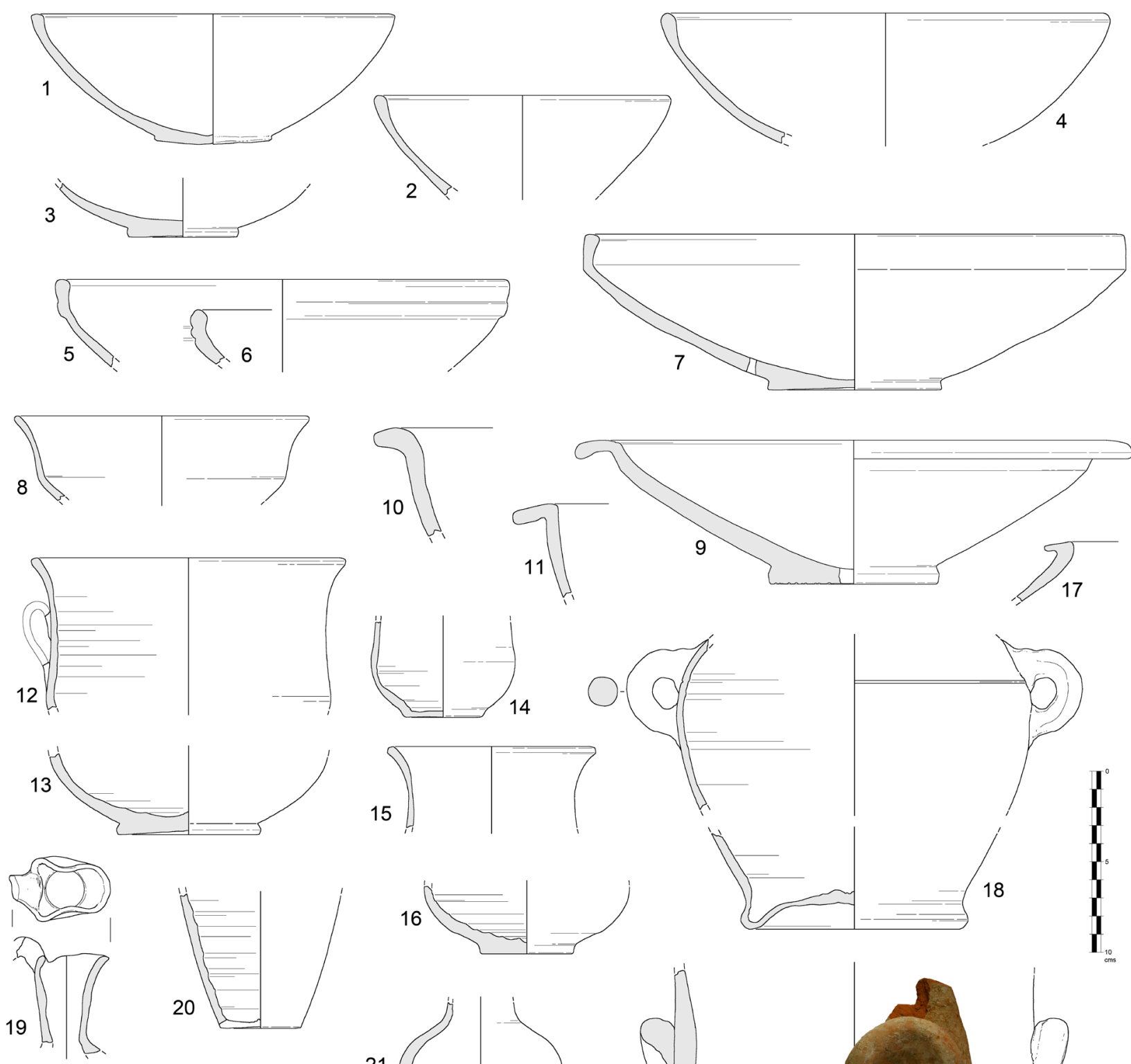

16
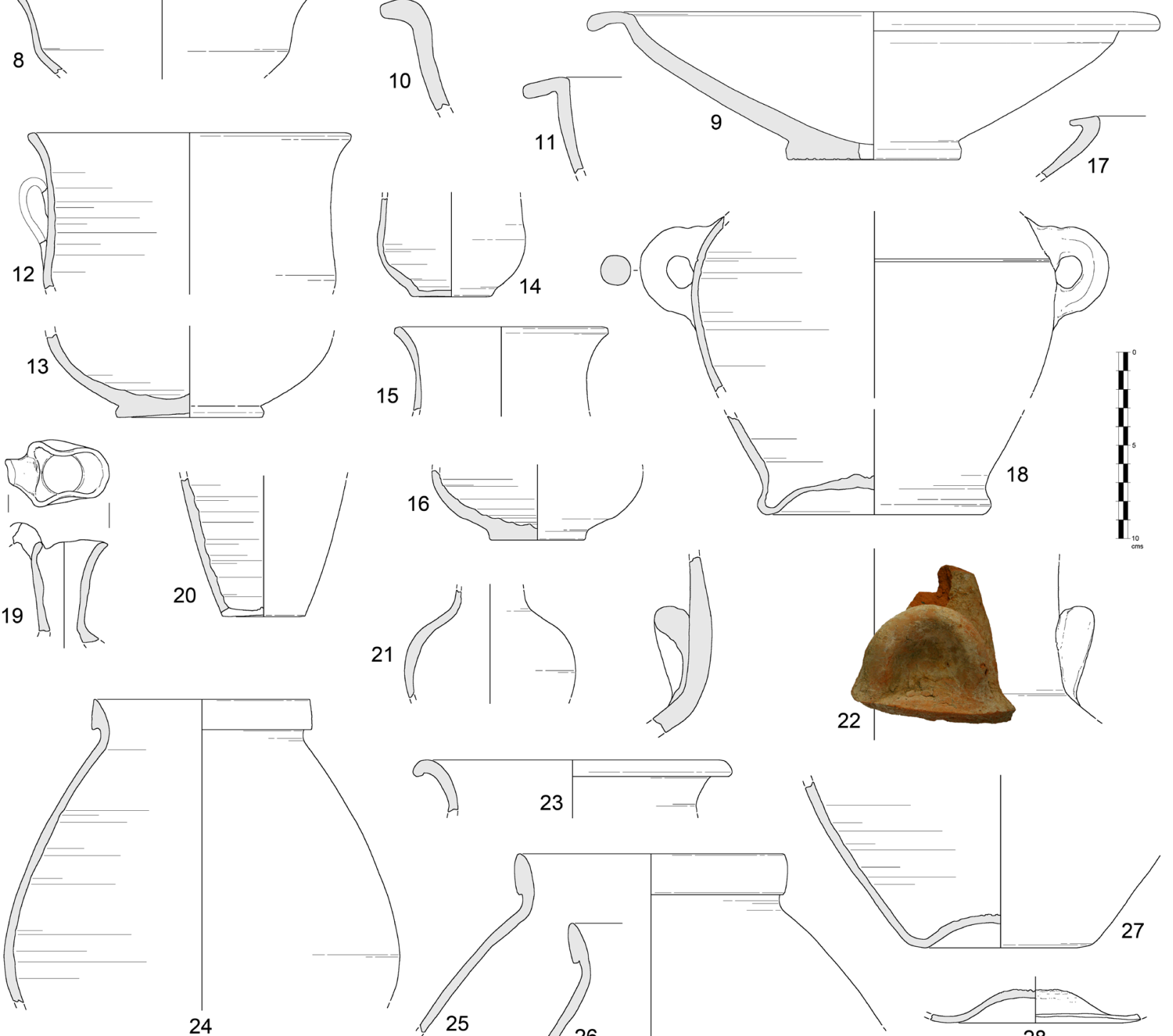

24

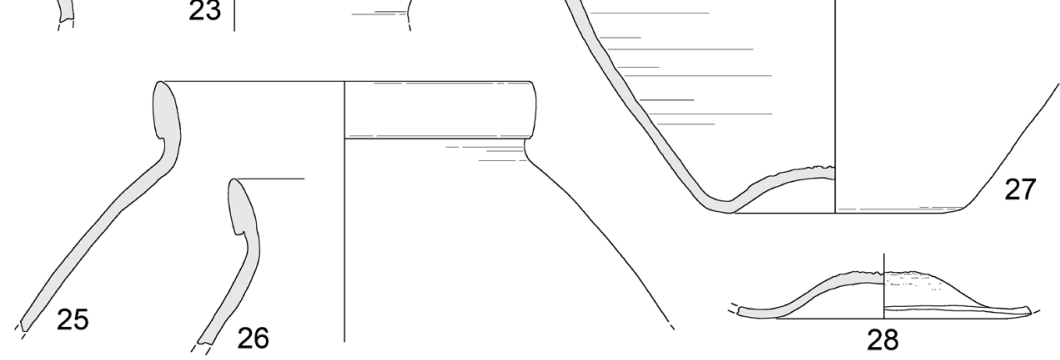

Figura 7. Cerámicas comunes de producción gaditana de la UE 09 (Esc. 1:4).

Revista Atlántica-Mediterránea de Prehistoria y Arqueología Social 22, pp. 109-137 
que las anteriores. Finalmente, dentro de este grupo debemos incluir también algunas muestras de asideros horizontales relacionados en algunos casos con estas cazuelas tardopúnicas (Figura 8: 17) y en otros con otras cazuelas de menor tamaño probablemente más antiguas (Figura 8: 21) similares a las presentes en algunos contextos de Villa Maruja (PPKK 220-229).

El conjunto de materiales recuperado en la UE 09 del horno de Calle Real permite intuir la existencia de una producción mixta en el taller, con un peso importante de los envases de transporte pero menos abrumador que el detectado en otros alfares insulares. El componente local es casi absoluto en el depósito, estando las importaciones representadas exclusivamente por ánforas (NMI 2; un 0,6\% del total cerámico), cuya presencia puede considerarse reflejo de la llegada a estos enclaves artesanales de productos destinados al consumo de los artesanos. El grueso del material del estrato parece indicar que la estructura terminó del colmatarse en un momento final del siglo III o muy inicial del II a.C., sobre todo si tenemos en cuenta el conjunto de barniz rojo local y la tipología de las ánforas locales, que muestran claras afinidades con conjuntos de materiales fechados en ese lapso en otros alfares gadiritas como Torre Alta (Horno 5; Sáez, 2008b), y diferencias con otros ya fechados al inicio del siglo II a.C. como el conchero de Luis Milena (Bernal et al., 2011) o vertidos del testar del Sector II de la campaña de 1995 en Torre Alta (Sáez et al., 2016). Las residualidades detectadas entre las ánforas o la vajilla barnizada permiten asimismo demostrar la existencia de fases de actividad muy anteriores al horizonte de colmatación del horno, con materiales que parecen relacionarse con una posible puesta en funcionamiento del horno en el siglo V a.C. (T11210, T-8211, platos de pescado, etc.).

El estrato ceniciento de color negro (UE 10) proporcionó una cantidad de materiales menor pero igualmente significativos para la caracterización del momento de colmatación. Entre las
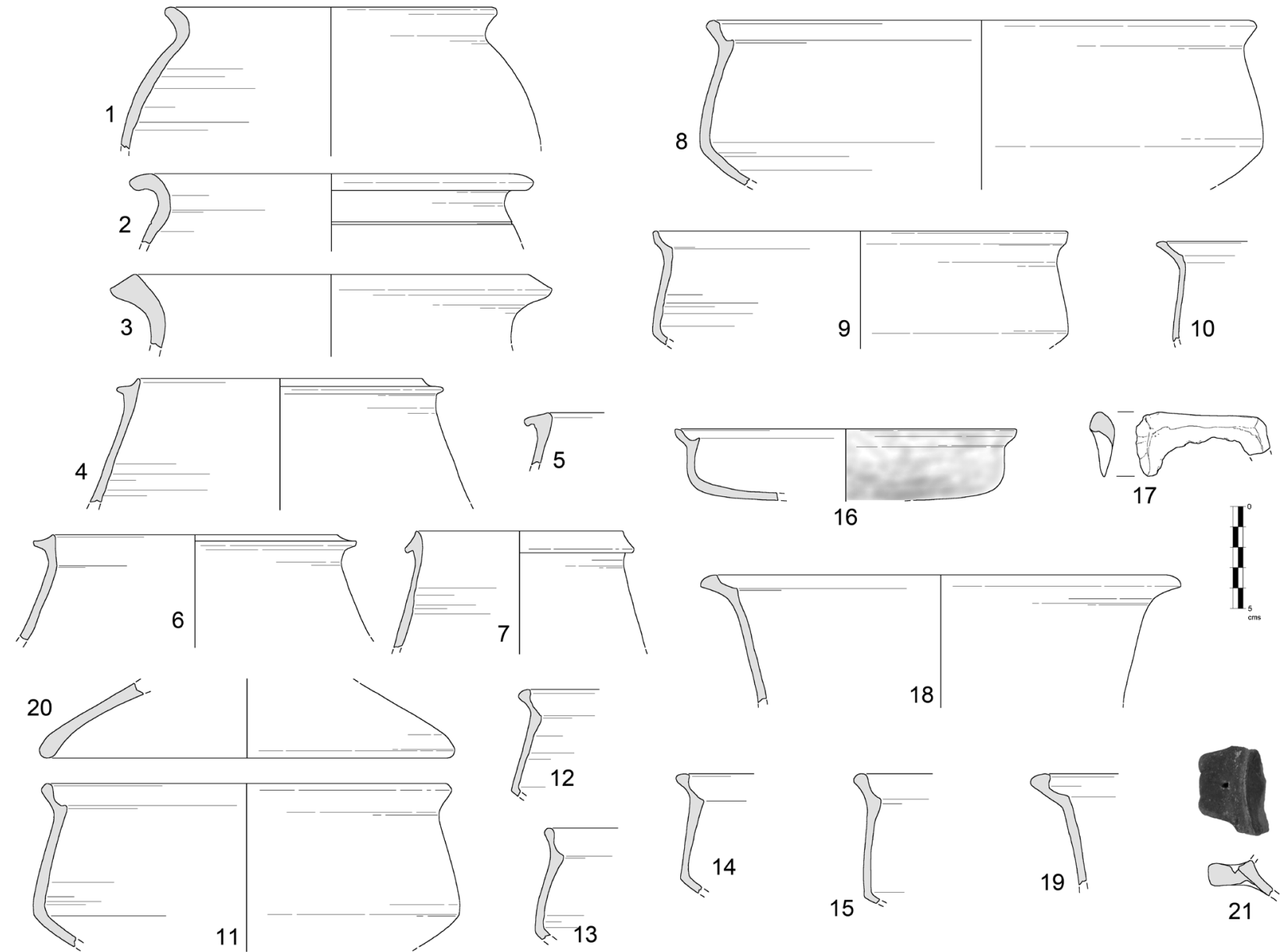

Figura 8. Ollas y cazuelas con pastas refractarias recuperadas en la UE 09 (Esc. 1:4). 
ánforas destacan en número los envases acilindrados del grupo T-8211 (Figura 9: 3-6). En general presentan diámetros estrechos, bordes alargados y verticales diferenciados de la pared y una acanaladura simple o doble a la altura de las asas, pequeñas y casi semicirculares. De esta forma se localizaron asimismo algunos desechos plenamente identificables, consistentes en porciones de labios de color verdoso deformados y parcialmente estallados pero con tipologías similares a los ejemplares no sobrecocidos. La Serie 1 de la producción gadirita apenas está representada gracias a la presencia de un ejemplar de T-11214/5 residual (Figura 9: 1) y de un borde de T-12111/2 con una tosca incisión sobre la zona superior del labio de notable anchura (Figura 9: 2). Por su parte, el tipo T-9111 está representado por varios fondos rehundidos de paredes gruesas (Figura 9: 9-11) así como por un par de bordes cortos y ligeramente engrosados al exterior (Figura 9: 7-8). Como en la UE 09, la presencia de interpretaciones locales de modelos grecoitálicos antiguos está atestiguada a partir de un pivote hueco (Figura 9: 12) y diversos fragmentos de hombros/espalda (Figura 9: 13) que describen formas con cuerpos de tendencia piriforme. A estas producciones locales debemos sumar un fragmento de pared de ánfora turdetana indeterminada, el cual presenta las típicas pastas depuradas de los valles del Guadalete o Bajo Guadalquivir (quizá una Pellicer D, aunque con rasgos distintos a la de la UE 09).

La vajilla barnizada se reduce en este estrato a una pequeña copa del tipo Niveau VIII con cubierta de barniz rojo total en el interior y exterior (Figura 9: 14). Mucho más abundantes son las diversas formas fabricadas en pastas comunes sin tratamiento de las superficies: vasos de gran formato con asa de sección aplanada del tipo GDR-7.2.1 (Figura 9: 18), cuencos de cuarto de esfera del tipo GDR-1.2.0 (Figura 9: 15-16), páteras carenadas del tipo GDR-2.1.0 (Fig. 9: 17) y tinajas sin asas del tipo GDR-8.1.1 (Figura 9: 19-22). Una de las páteras documentadas (varios fragmentos del mismo ejemplar) presenta una característica adherencia arcillosa interior en la cual se aprecian huellas de digitaciones probablemente dejadas por un artesano al limpiarse las manos del sobrante de este material. Es posible por tanto que se trate de un recipiente auxiliar empleado en las labores alfareras para contener algún tipo de barbotina, quizá relacionada con la adición de elementos de aprensión o retoque de las piezas en fresco. Finalmente, la cerámica "de cocina" de nuevo parece dominada cuantitativamente por cazuelas del tipo 11.3.0 (Figura 9: 23-25) y posiblemente también GDR11.2.1 (Figura 9: 26), así como apliques horizontales asociados a estos mismos tipos (Figura 9: 27).

El contenido material de la UE 10 refleja de nuevo indirectamente el posible desarrollo en el enclave de una producción mixta en la que las ánforas no suponen el aporte principal de la muestra, aunque sí una parte muy apreciable del volumen total de individuos, en el cual sólo un ánfora de origen turdetano vuelve a ser el único elemento de importación $(1,72 \%$ del total cerámico). Hay que destacar también la menor incidencia de elementos residuales en este estrato (sólo un borde de T-11214/5, fechable quizá a finales del siglo V o principios del IV a.C.). Por el contrario, el resto de materiales sugiere una datación cercana al tramo final del siglo III a.C. o poco posterior a esta fecha.

El estrato depositado sobre la parrilla del horno (UE 11) proporcionó un número similar de ítems que la UE 10, relacionados en este caso con los primeros momentos de colmatación interna de la cámara de cocción. Entre ellos, las ánforas vuelven a tener un espacio destacado: por un lado, diversos fragmentos y bordes de T-12111 (Figura 10: 1-3 y 5) de morfologías diversas propias del siglo IV a.C. (Sáez, 2019); por otro, un buen número de T-12111/2 de labios engrosados y acanalados (Figura 10: 4 y 6-7); asimismo, varios individuos del tipo T-9111 (Figura 10: 14-15) e imitaciones de grecoitálicas (Figura 14: 16-17), estas últimas con cuerpos de paredes finas que conforman cuerpos piriformes de notable volumen. Sin embargo, como en el resto del relleno del laboratorio, el grupo dominante está compuesto por ejemplares de la Serie 2 gadirita: en primer lugar, dos bordes del grupo T-8211 (Figura 10: 9-10) de amplio diámetro que parecen piezas residuales; asimismo, más de una docena de ejemplares evolucionados del mismo tipo, de similares características a los recuperados en las UUEE 09-10 (Figura 10: 11-13), a lo que tendríamos que sumar la documentación de varios fondos ojivales simples adscribibles a esta misma forma.

No se han documentado en este estrato restos de vajilla barnizada o pintada, ni local ni importada, lo que sin embargo no es indicio contundente de que nos encontremos ante una fase productiva diferenciada, dadas las claras conexiones crono-tipológicas observadas en el resto del material que parecen mostrar una destacada sincronía en todo 

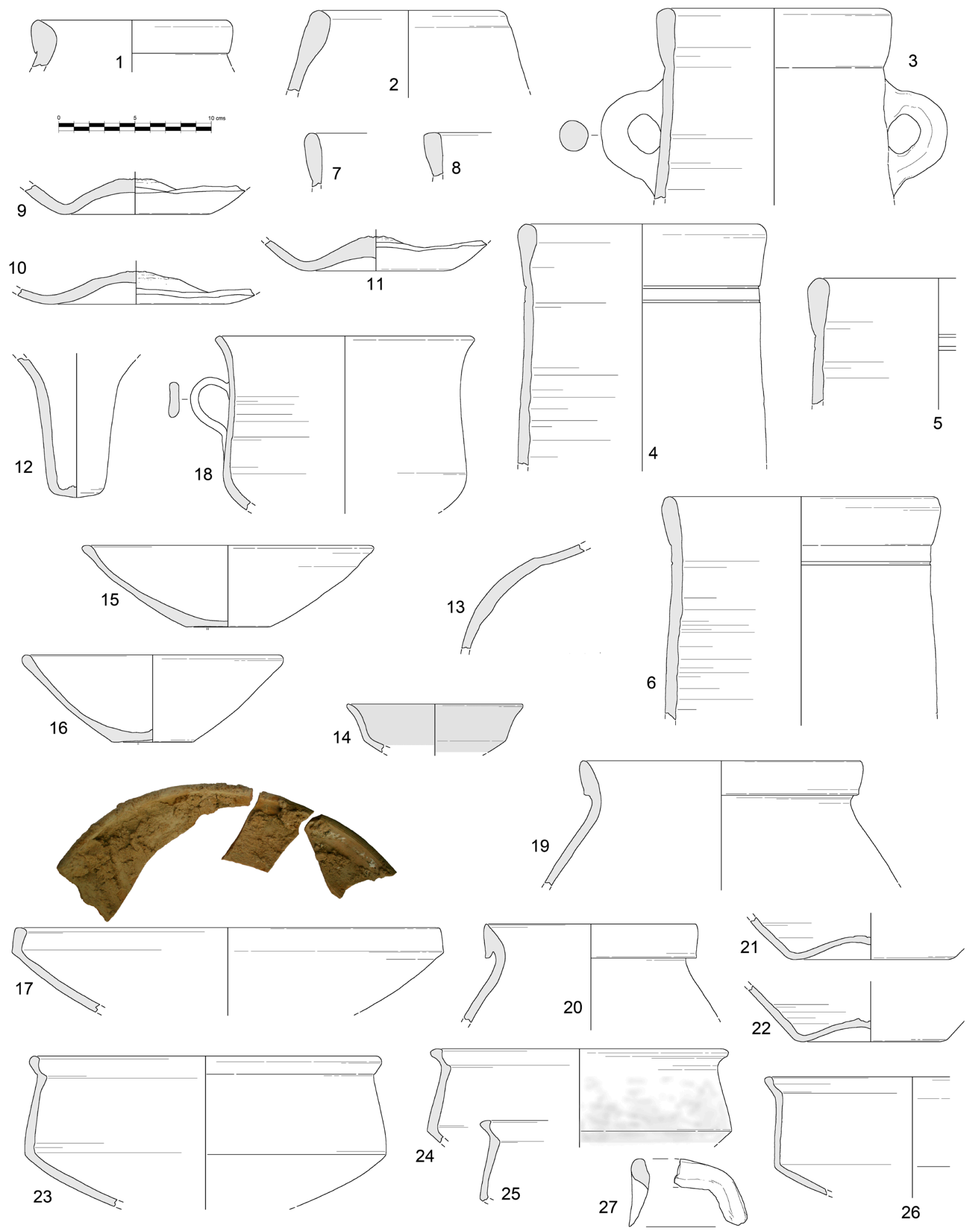

Figura 9. Materiales cerámicos de producción local de la UE 10 (Esc. 1:4).

Revista Atlántica-Mediterránea de Prehistoria y Arqueología Social 22, pp. 109-137

Universidad de Cádiz 

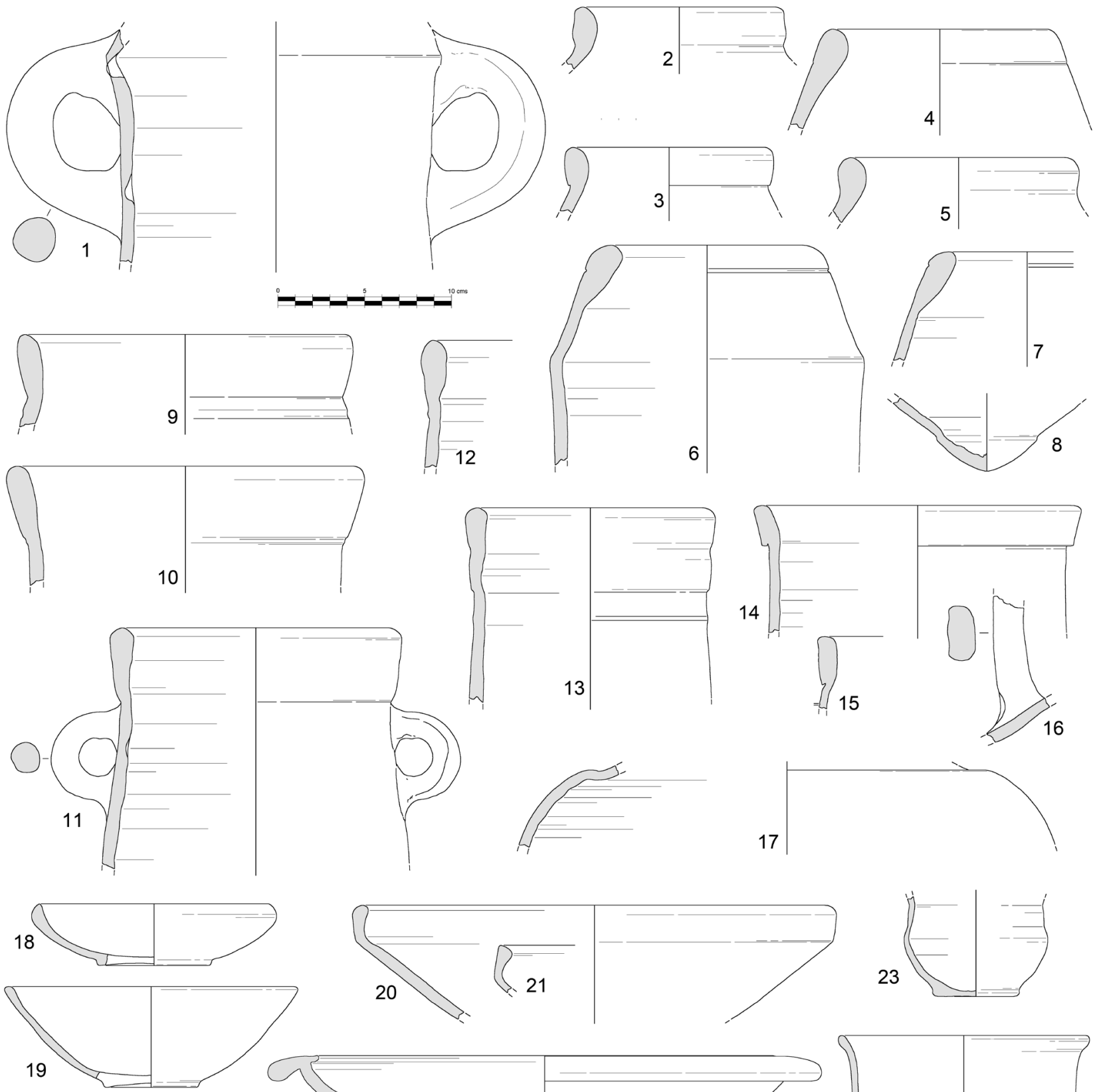

(1)
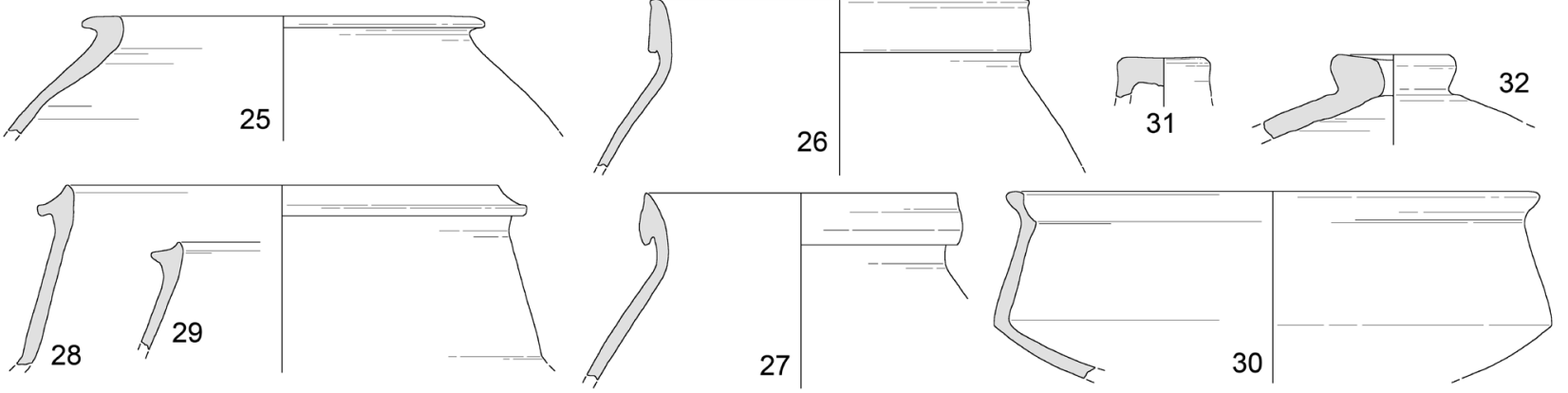

Figura 10. Ánforas, cerámicas comunes y "de cocina” de la UE 11 (Esc. 1:4).

Revista Atlántica-Mediterránea de Prehistoria y Arqueología Social 22, pp. 109-137

Universidad de Cádiz 
el relleno del laboratorio del nuevo horno. Sí son, por el contrario, relativamente numerosas las cerámicas comunes sin tratamiento de fábrica local. De entre las formas abiertas destacan los cuencos de cuarto de esfera profundos (Figura 10: 19), así como versiones de destacable diámetro del GDR1.1.0 (Figura 10: 18). Más numerosas aún son las páteras carenadas del tipo GDR-2.1.0 (Figura 10: 20-21), acompañadas por platos-morteros de una variante del GDR-3.2.1 dotada de una pequeña pestaña proyectada al interior (Figura 10: 22) así como de vasos tanto de gran tamaño del tipo GDR7.2.0 (Figura 10: 24) como de talla reducida para el servicio de mesa (Figura 10: 23). A este grupo de formas abiertas podemos añadir una tapadera o plato-tapadera reversible dotado de perforación precocción en el centro del pomo (Figura 10: 32), forma que cuenta con paralelos en Torre Alta (Sáez, 2008b) y en la necrópolis tardopúnica gaditana (Niveau de Villedary, 2009: 135, fig. 102).

Las formas cerradas comunes se reducen en la UE 11 a dos grupos: abundantes tinajas del tipo GDR-8.1.1 (Figura 10: 26-27) y un individuo de las tinajas cartaginizantes de la forma GDR-12.2.2 inspiradas en el tipo Cintas 224 (Figura 10: 25). El resto de las cerámicas del estrato corresponde a producciones con pastas refractarias "de cocina": ollas del grupo GDR-12.3.0 (Figura 10: 2829), cazuelas de la forma GDR-11.3.1 (Figura 10: 30), GDR-11.2.1 y otras de pequeño tamaño de la variante GDR-11.3.3, a las que hay que sumar el pomo simple de una posible tapadera relacionada con el uso de estas ollas/cazuelas (Figura 10: 31).

El examen cuantitativo de los materiales de la UE 11 aporta similares conclusiones que las ya esbozadas para las otras dos unidades del relleno del laboratorio, aunque en este caso no se han documentado importaciones de ninguna clase. En cuanto a la datación del estrato, debemos señalar que la incidencia de residualidad entre las ánforas es significativo (con varias T-12111 y T-8211, propias del siglo IV a.C.), si bien el resto del conjunto muestra una homogeneidad destacada y vuelve a conducirnos a un momento cercano a la transición de los siglos III-II a.C. con paralelos repetidamente citados en las áreas funerarias, habitacionales y artesanales conocidas en la bahía gaditana.

El estudio estadístico básico global de los tres contextos refleja con claridad el carácter mixto de la producción y el peso específico de las ánforas (Figuras 11 y 12). Aunque el análisis está condicionado por los ya citados fenómenos de residualidad documentados en el depósito y por la consabida mayor fragmentación del material común de pequeño porte (que genera más individuos y obliga a ser cautos a la hora de valorar su verdadera entidad numérica comparada), podemos afirmar que en su fase tardopúnica el taller debió concentrar buena parte de sus esfuerzos en el torneado de ánforas de los tipos T-8211, 12111/2 y T-9111, además de imitaciones de ánforas grecoitálicas, panorama que coincide plenamente con lo estudiado anteriormente en otros muchos alfares insulares gaditanos (múltiples ejemplos en Sáez, 2008b). La relación de las T-11210, T-12111 y T-8211 antiguas documentadas en estos contextos con la fase inicial de uso del horno, durante los siglos V-IV a.C. es mucho más difícil de establecer, aunque a la vista de algunos de los paralelos citados no puede descartarse una conexión entre estos materiales residuales y este $\mathrm{u}$ otros hornos o vertederos situados en las cercanías.

La producción de cerámicas comunes y de cocina (ollas, cazuelas y tapaderas) también debió de alcanzar un notable nivel, con un repertorio variado y con rasgos compartidos con otros talleres cercanos, que a nivel formal no desdice las apreciaciones observadas en las ánforas y que, si consideramos el número de individuos, representó más del $60 \%$ de la producción. La vajilla de barniz rojo, aún incluyendo algunas piezas residuales de momentos de actividad más antiguos, alcanza cifras notablemente más bajas (apenas un 5\% del total) que parecen sugerir que si bien se dio su fabricación en el alfar, ésta debió estar relacionada con otras estructuras de cocción cercanas y no específicamente con este horno.

Si bien no podemos verificar a través de los contextos analizados qué produjo específicamente el horno, las cerámicas presentes en su interior nos ilustran parcialmente sobre cuáles debieron ser los tipos habitualmente torneados en el taller, y ocasionalmente algunos elementos usados por los propios alfareros para su consumo (caso de algunas cazuelas con huellas de exposición al fuego o de la pátera carenada usada para contener arcilla). El carácter mixto de la producción cerámica de la zona de Calle Real 210-212 que se infiere indirectamente de estos contextos es, por otro lado, la combinación habitual hallada en estos talleres insulares de Gadir. Este hecho denota el carácter aún de estas instalaciones como enclaves artesanales diferenciados, con un volumen de producción limitado pero también con un repertorio muy 


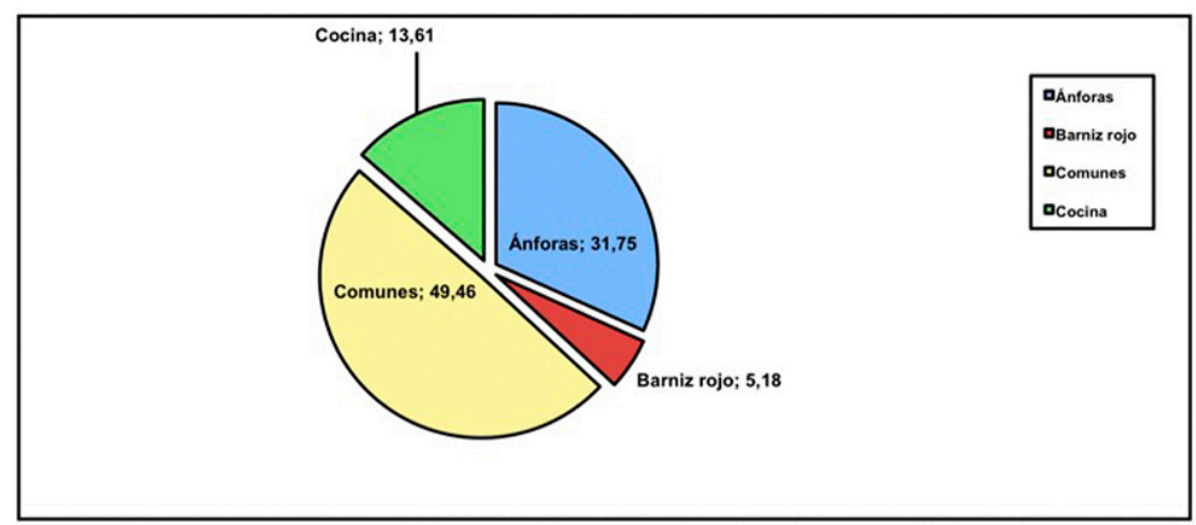

\begin{tabular}{|l|c|c|c|c|c|c|}
\hline & Ánforas & Barniz rojo & Comunes & Cocina & TOTAL \\
\hline \% & 30,33 & 6,91 & 48,65 & 14,11 & 100 \\
\hline NMI & 101 & 23 & 162 & 47 & 333 \\
\hline & Ánforas & Barniz rojo & Comunes & Cocina & TOTAL \\
\hline \% & 32,76 & 1,72 & 56,9 & 8,62 & 100 \\
\hline NMI & 19 & 1 & 33 & 5 & 58 \\
\hline \multicolumn{7}{|c|}{ UE 11 } \\
\hline \% & Ánforas & Barniz rojo & Comunes & Cocina & TOTAL \\
\hline NMI & 27,5 & - & 47,22 & 15,28 & 100 \\
\hline & & - & 34 & 11 & 72 \\
\hline & Ánforas & Barniz rojo & Comunes & Cocina & TOTAL \\
\hline \% & 31,75 & 5,18 & 49,46 & 13,61 & 100 \\
\hline NMI & 147 & 24 & 229 & 63 & 463 \\
\hline
\end{tabular}

Figura 11. Resumen de la distribución cuantitativa de las cerámicas documentadas en el relleno del laboratorio del horno excavado en la Calle Real.

similar en el cual es evidente el protagonismo de la producción anfórica (relacionada con el envasado de las conocidas salazones de pescado gadiritas). La presencia de algunas importaciones, en este caso dos ánforas turdetanas del tipo Pellicer D y una T-12111 (quizá tingitana o malacitana) atestigua, como en otros talleres, el consumo esporádico por los alfareros de productos foráneos probablemente como parte de su dieta (aunque con una aportación mínima en el conjunto global: 3 individuos, un $0,65 \%$ del total cerámico).
2.2.2. Los materiales de la "Fosa de trabajo" (UE 03)

Aunque no fue posible excavar la cámara de combustión del horno, sí se pudo examinar una pequeña porción de lo que hemos interpretado como la "fosa de trabajo" subterránea que daría acceso al corredor del horno. Su relleno, aparentemente homogéneo y compuesto por tierra grisácea, cenizas y fragmentos de adobes y cerámicas, fue denominado UE 03. Esta composición 


\begin{tabular}{|c|c|c|c|c|c|c|c|c|c|}
\hline & & & & & E 09 & & & & \\
\hline & T11210 & T12111 & $\mathrm{T} 12111 / 2$ & T8211 & T9111 & Grecoitálica & T12111 & Turdet & TOTAL \\
\hline$\%$ & 4,95 & 7,92 & 15,84 & 54,46 & 8,91 & 5,94 & 0,99 & 0,99 & 100 \\
\hline NMI & 5 & 8 & 16 & 55 & 9 & 6 & 1 & 1 & 101 \\
\hline & & & & & E 10 & & & & \\
\hline & T11210 & T12111 & $\mathrm{T} 12111 / 2$ & T8211 & T9111 & Grecoitálica & T12111 & Turdet & TOTAL \\
\hline$\%$ & 5,26 & - & 5,26 & 63,16 & 15,79 & 5,26 & - & 5,26 & 100 \\
\hline NMI & 1 & - & 1 & 12 & 3 & 1 & - & 1 & 19 \\
\hline & & & & & E 11 & & & & \\
\hline & T1323 & T12111 & $\mathrm{T} 12111 / 2$ & T8211 & T9111 & Grecoitálica & T12111 & Turdet & TOTAL \\
\hline$\%$ & 7,41 & 14,81 & 11,11 & 55,55 & 7,41 & 3,7 & - & - & 100 \\
\hline NMI & 2 & 4 & 3 & 15 & 2 & 1 & - & - & 27 \\
\hline & & & & & DTAL & & & & \\
\hline & T11/T1 & T12111 & T12111/2 & T8211 & T9111 & Grecoitálica & T12111 & Turdet & TOTAL \\
\hline$\%$ & 5,44 & 8,16 & 13,6 & 55,78 & 9,52 & 5,44 & 0,68 & 1,36 & 100 \\
\hline NMI & 8 & 12 & 20 & 82 & 14 & 8 & 1 & 2 & 147 \\
\hline
\end{tabular}

Figura 12. Desglose cuantitativo de Número Mínimo de Individuos (NMI) y porcentajes de las ánforas documentadas en los estratos del relleno del laboratorio del horno excavado en la Calle Real.

de su matriz y la existencia de paralelos en Torre Alta (MC-II) y otros talleres sugiere que una vez el horno cayó en desuso este espacio fue colmatado rápidamente con los resultados de las limpiezas periódicas del taller y los hornos circundantes, por lo que probablemente el material asociado corresponda tanto a elementos residuales de las últimas fases de actividad como sobre todo a los momentos inmediatamente posteriores al abandono. El análisis de los materiales de este vertedero, aún no totalmente concluido, aporta un contrapunto de enorme interés para intentar fijar la cronología de amortización de la estructura fornácea anexa ya que ésta no pudo funcionar a partir de que la fosa de trabajo hubiese estado ya rellena (y por tanto inutilizando el propio corredor del horno).

El análisis preliminar de los materiales ha mostrado una exuberante presencia de envases de transporte. Así, entre las ánforas los elementos residuales del tipo T-11210 se presentan en un número nada despreciable (NMI 43), la mayoría con labios triangulares y espaldas más o menos rectas, con algunos bordes alargados similares a los documentados en los testares de Villa Maruja (Bernal et al., 2003). Sin embargo, los envases T-12111 son la variante más numerosa en el contexto (NMI 78), estando las T-12111/2 con labio inciso al exterior presentes de forma casi testimonial (NMI 7). Respecto a las producciones locales del SG-8, mientras que de las variantes más antiguas apenas se han podido identificar unos pocos ejemplares (NMI 7) la presencia de T-8211 con perfiles propios de pleno siglo IV y primera mitad del III a.C. es masiva (NMI 82), siendo escasísimas las posibles T-8211 evolucionadas (NMI 3). También se documentan otros tipos anfóricos locales, como el T-9111 (NMI 4) o imitaciones de grecoitálicas antiguas (NMI 1), más ampliamente representados en el interior del horno. Las importaciones anfóricas son en esta UE 03 muy minoritarias, correspondiendo únicamente a ejemplares de ánforas acilindradas turdetanas de tipología imprecisable (NMI 2).

Entre los ejemplares de la variante más abundante del tipo T-8211 debe inscribirse además el hallazgo de un sello de cartela ovalada estampado sobre la pared a la altura de la acanaladura de inserción de las asas bajo el borde (Figura 13, abajo), mostrando una iconografía antropomorfa consistente en un prótomo mirando hacia la derecha tocado con un gorro cónico tipo pileus, sin que puedan apreciarse más detalles debido a la deficiente calidad de la impresión y a la erosión sufrida por la pieza. La posición del sello es 

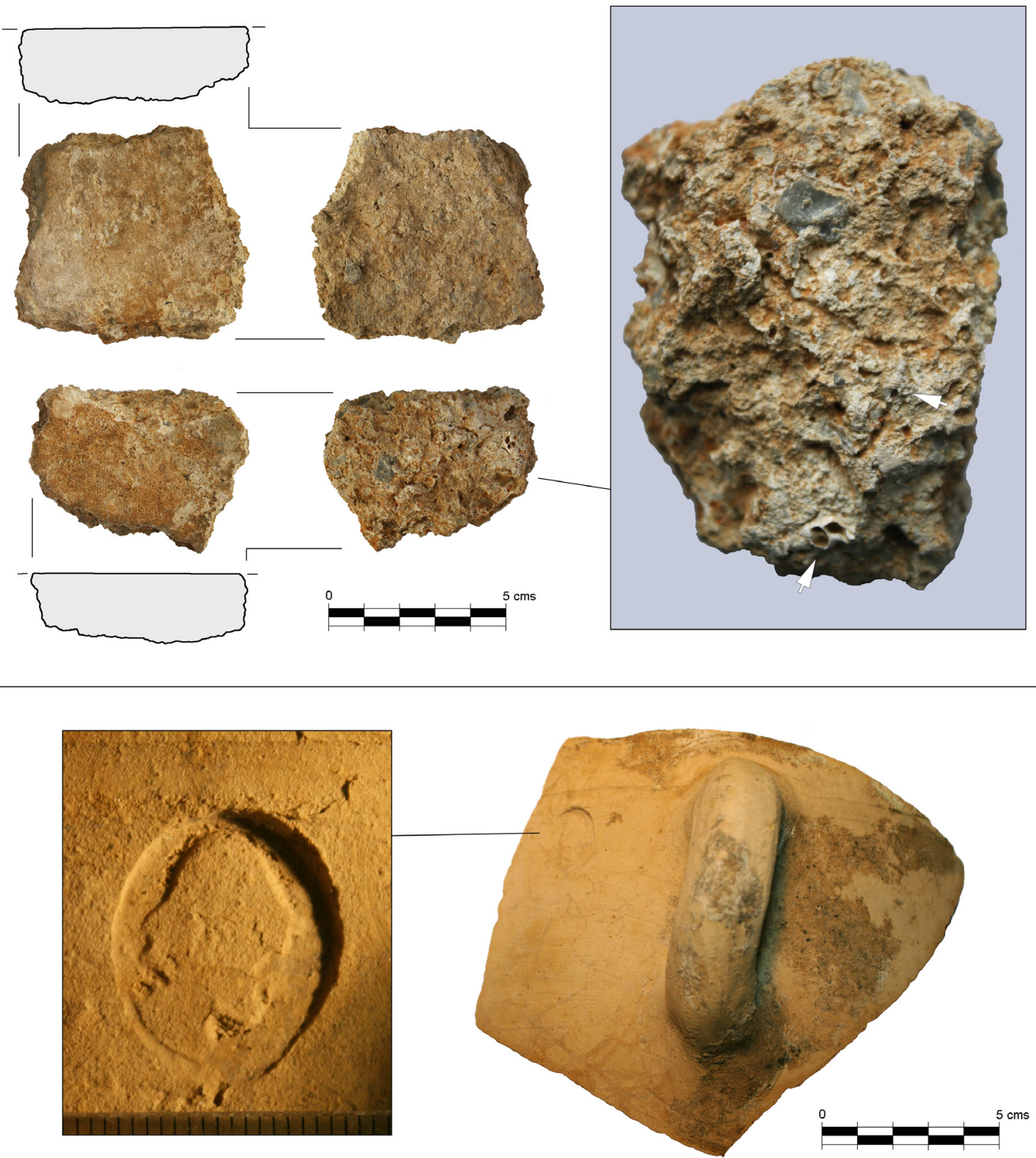

Figura 13. Fragmentos de mortero de cal con conchas (arriba) y sello estampado sobre fragmento de pared y asa de un ánfora tipo T-8211 recuperado en los vertidos de la "fosa de trabajo" anexa al horno (sello a escala 2:1, aproximadamente).

la habitual en este grupo de envases, y probablemente corresponde a los ejemplos más antiguos de esta práctica en ámbito local, fechables entre avanzado el siglo IV y los inicios del III a.C. Se trata posiblemente del mismo cuño documentado en otra impronta estampada sobre un borde de T-8211 en el área de Villa Maruja - Janer (Sáez y Belizón, 2018), o al menos de una versión de la misma iconografía, de cara inspiración monetal.
En trabajos recientes hemos destacado las analogías con ciertos tipos de las acuñaciones malacitanas que parecen representar a Chusor-Ptah o Kusor, quizá una interpretatio de Hefesto/Vulcano, que en cualquier caso podría aludir tanto a un emblema personal o familiar de un personaje vinculado al negocio alfarero como a una divinidad de carácter artesanal (Sáez y Ferrer, 2018: 284-285 y 294). Este nuevo hallazgo permite 
establecer interesantes conexiones entre ambas zonas productoras, separadas por menos de 1 $\mathrm{km}$ de distancia lineal, planteando la posibilidad de que ambas pudieran haber sido explotadas (al menos puntualmente) por los mismos artesanos o gestores. En cualquier caso, este nuevo sello amplía la ya amplia nómina de improntas documentadas sobre las ánforas púnicas gadiritas, atestiguando un fenómeno que probablemente fue de la mano con transformaciones en los modelos de gestión y de monetización de la economía local y regional.

La vajilla de mesa barnizada es escasa en la "fosa de trabajo", con un repertorio con notables diferencias con el documentado en el interior del laboratorio: por un lado, varios platos y cuencos hemiesféricos con engobe rojo al interior (NMI 5); por otro, varios platos L23 con cubierta total de barniz integrantes del repertorio local de tipo helenístico (NMI 3). Un sólo ejemplar de plato de pescado tosco, fabricado en pasta gris local, completa el conjunto de vajilla gadirita. Junto a esta exigua muestra, una pared de tinaja mediana con bandas externas de rojo vinoso y pasta muy depurada parece testimoniar la existencia en el contexto de importaciones pintadas de origen turdetano, quizá acompañantes originalmente de los envases de transporte.

Las cerámicas comunes son más abundantes y más diversas formalmente. Entre ellas podemos destacar la presencia de platos de pescado (NMI 7), saleritos (NMI 2), cuencos hemiesféricos o de cuarto de esfera GDR-1.2.0 (NMI 35), páteras carenadas del tipo GDR-2.1.0 (NMI 12, de ellos cuatro con doble acanaladura sobre el labio), platos-mortero cercanos al perfil de los GDR-3.2.1 (NMI 4), un plato moldurado (similar a uno localizado en el nivel II del testar de los PPKK 220-229 de VM), lebrillos (NMI 20), vasos del grupo GDR-7.0.0 (NMI 5), jarritas de tipo olpe GDR-10.2.0 (NMI 4), un solo enocoe trilobulado quizá del GDR-10.3.0, y tinajas de la forma GDR-8.1.1 (NMI 33). También fabricadas en pastas comunes documentamos dos fragmentos de pondera asimilables al tipo GDR-14.3.1 aunque de menores dimensiones y con las perforaciones más centradas. Por su parte, el repertorio de cocina (NMI 22) estaba compuesto íntegramente por producciones locales, siendo mayoritarias las ollas GDR-12.3.0 o de tipo globular, junto a algunas cazuelas del grupo GDR-11.2.1/11.3.0 o modelos precursores de ellas (sobre la cerámica "de cocina”, vide Sáez, 2018).

\section{Discusión y conclusiones}

La excavación preventiva llevada a cabo en 2009 puso al descubierto apenas una pequeña parte de lo que debe ser un asentamiento artesanal de mayor envergadura, cuyo conjunto principal de estructuras debe permanecer aún oculto bajo las parcelas ocupadas por los números 210 y 212 de la Calle Real y el pequeño callejón Diputado Ciscar. El horno exhumado parcialmente permite, no obstante, plantear de forma preliminar interesantes consideraciones acerca de su tecnología fornácea, de la cronología de la actividad alfarera en la zona y de las conexiones del enclave con otros talleres insulares. En relación a los datos inéditos relativos a los aspectos tecnológicos que aporta el estudio de la actuación en la Calle Real, además de lo ya descrito para el caso del propio horno (con paralelos cercanos en Camposoto y Villa Maruja - Janer), resalta el que de nuevo el material presente en el relleno del laboratorio pone de relieve la complejidad de análisis diacrónico de la funcionalidad de estos espacios artesanales.

En concreto, el hallazgo de dos fragmentos de mortero de cal de pequeñas dimensiones, similar al cocciopesto romano utilizado para recubrir suelos, canalizaciones y piletas (Figura 13, arriba), abre la posibilidad de que al menos en la fase tardopúnica se ubicasen en este punto cubetas impermeabilizadas. En ambos fragmentos se observa la presencia de árido pétreo de escaso porte y de restos de malacofauna de talla pequeña ( $T u$ rritella communis). Se trata de en este segundo caso de un ingrediente muy característico de los morteros hidráulicos con base de cal utilizados en el ámbito gaditano en fábricas conserveras, estando presente en el caso citado de Luis Milena y en otros ejemplos de época republicana e imperial inicial. Un primer avance de un estudio sistemático (arqueológico y arqueométrico) se presentó al congreso El empleo de morteros y cales en la arquitectura romana. De sus antiguas propiedades a las nuevas técnicas de análisis para su caracterización, celebrado en la Universidad de Sevilla (23-25 de noviembre de 2017) y cuyas actas se encuentran aún en prensa. Tomando en consideración otros casos relevantes como Luis Milena, muy cercano y de similar cronología (Bernal et al., 2011: 165166, fig. 12; Sáez, 2008b: 356-365), no podemos descartar que pueda tratarse de residuos producidos fruto de una gran reforma de las instalaciones, y que la funcionalidad de estas infraestructuras no 
fuese únicamente alfarera sino también pesquero-conservera.

Respecto a la cronología, como expusimos en el apartado anterior, las analogías del modelo arquitectónico del horno primigenio lo vinculan directamente con la fase tardoarcaica de Camposoto y otros talleres locales, lo que permite tentativamente presumir una construcción de la estructura en el siglo $\mathrm{V}$ a.C. Adicionalmente, la presencia de un porcentaje significativo de elementos claramente residuales en el depósito de relleno del laboratorio, testimonian el desarrollo de actividades alfareras en el lugar entre los siglos V-IV a.C., destacando la presencia de ánforas de los tipos T-11210, T-12111 y T-8211 (variantes antiguas), y algunas formas comunes e ítems con cubierta de barniz rojo parcial (cuencos, platos). Como ya se ha adelantado, estos limitados indicios sólo permiten situar hipotéticamente el momento de construcción y uso inicial de la estructura pero, lamentablemente, no realizar una lectura definitiva sobre si permaneció activa hasta la fase de reforma que condujo a dotarlo de la parrilla de barras o si por el contrario sufrió un proceso de abandono/ amortización y fue reacondicionado mucho después (modificando la cámara, UE 07) y dotándolo de un nuevo suelo para el laboratorio.

El contexto material documentado en el interior de la posible fosa de trabajo del horno (UE 03) parece certificar la existencia de horizontes productivos al menos desde la segunda mitad del siglo V a.C. (asociación de T-11214/5 y versiones locales del T-1323) en el entorno inmediato a este punto. Sin embargo, el grueso del material presente en la unidad parece remitir a una fase más tardía de actividad centrada en pleno siglo IV o el siglo III a.C. En estos rellenos de la fosa de trabajo los elementos anfóricos más tardíos son los cuantitativamente menos significativos (T-12111/2, T-8211, T-9111, grecoitálicas locales, todos ellos con unos 5 o menos individuos), lo cual resulta revelador respecto a un uso tardío de la estructura fornácea que se llevó a cabo sobre una fosa ya parcialmente colmatada por ítems de los siglos V-IV a.C.

En el mismo sentido, el contenido cerámico de la cámara de cocción del horno también sugiere un cegamiento total de la cámara superior en torno al tramo final del siglo III o los inicios del II a.C., si atendemos a la mayoritaria presencia de ciertas tipologías de las ánforas locales y de algunos ítems de barniz rojo y comunes en las UUEE 9-11.
Como se ha tratado en el apartado anterior de forma pormenorizada, se trata en general formas características de estos momentos de transición entre la etapa bárquida y los inicios del dominio romano sobre la bahía. La asociación de tipos anfóricos es característica de esta época en los alfares gadiritas, como muestran las claras conexiones contextuales del horizonte de abandono del horno con otros depósitos alfareros como el Sector I de Torre Alta, los contextos de amortización del Horno I de La Milagrosa (Bernal et al., 2003), del Horno 2b de Camposoto (Sáez 2013: 228-230, fig. 5) o la escombrera de desechos alfarero-haliéuticos de Luis Milena (Bernal et al., 2011), así como con instalaciones conserveras abandonadas también a finales del siglo III a.C. como Puerto 19 (Sáez et al., 2020). Las afinidades en cuanto a la composición del contexto material del laboratorio pueden extenderse sin duda a los niveles de abandono de Castillo de Doña Blanca (Ruiz y Pérez, 1995: 7376, figs. 26-32) y a buena parte de los restos que de forma también genérica se han vinculado a la amortización de pozos y fosas en la necrópolis tardopúnica insular gadirita (Niveau de Villedary, 2009: passim).

De este modo, el estudio de los materiales y estructuras de la AAP de 2009 no sólo proporciona un nuevo apoyo contextual a la sistematización de los elementos muebles propios de estos horizontes, por ahora mayoritariamente tratados con escasa conexión con las estratigrafías de procedencia, sino que además aporta indicios de gran valor para la lectura de los complejos fenómenos de transformación del asentamiento gadirita entre la presencia de los Barca y el inicio del dominio romano. Se trató sin duda de unos años convulsos, en lo económico y en lo militar, que desembocaron en un cambio total del patrón de habitación y aprovechamiento de la bahía, con el abandono masivo de enclaves principales y secundarios en los rebordes costeros de la campiña (CDB, Chiclana, saladeros portuenses, etc.). Como se ha puesto de relieve en trabajos anteriores a propósito del saladero insular de Los Chinchorros (Sáez y Lavado, 2019), el territorio insular experimentó modificaciones importantes en el patrón de distribución de los enclaves artesanales, en el paso a una mayor multifuncionalidad de los mismos y en las tecnologías empleadas en la renovación de las infraestructuras. El citado caso de Luis Milena (dotado de piletas con mortero de cal, similares a los de los saladeros), así como los fragmentos de 
posibles piletas localizados en el horno de Calle Real o en Torre Alta (inéditos) ponen de relieve que muchos de los antiguos alfares púnicos pudieron ser "actualizados" en la etapa tardopúnica añadiendo estructuras conserveras a sus hornos cerámicos y talleres.

En cualquier caso, lo que testimonian este nuevo horno de Calle Real y el resto de los amortizados en torno al 206 a.C. es que dicha etapa pudo significar un final abrupto para la actividad de estos alfares dispersos (e indefensos) del territorio insular, del mismo modo que parece que lo fue para Castillo de Doña Blanca o los saladeros de la campiña costera portuense (Ruiz et al., 2006). Luis Milena, Pery Junquera o Torre Alta, entre otros, testimonian en el entorno de Calle Real que sin embargo la actividad retornó pronto a estos mismos puntos, quizá ya con ese modelo híbrido alfarero-conservero al que antes hacíamos referencia, y que parece tendría continuidad hasta solaparse y enlazar con las enormes reformas de la etapa tardorrepublicana (una exposición más amplia de estas cuestiones en (García y Sáez, 2018; Sáez y García, 2019). En esta zona, otras fosas situadas en las inmediaciones (hacia la calle Batallones de Marina) verifican la continuidad del poblamiento durante los siglos II-I a.C. y en época imperial romana, con unas funciones dificiles de determinar debido al arrasamiento casi total de las estructuras edilicias de estas fases (algunos desechos de ánforas Dr. 7/11 sugieren sin embargo la continuidad de la producción cerámica en las cercanías).

En definitiva, el hallazgo de este nuevo horno púnico gaditano y de los vertederos diseminados en su entorno confirma en buena medida los supuestos dados a conocer hace más de una década (Sáez, 2008a, 2008b) acerca del patrón territorial de implantación de estas áreas alfareras en el hinterland rural de Gadir, permitiendo definir su interacción con otras áreas artesanales circundantes como El Canal, Torre Alta, Batallones de Marina o Luis Milena. La distribución de estos puntos, no alejados entre sí más de 300/350 m, muestra una constante muy semejante a la observada para los saladeros portuenses coetáneos (Ruiz et al., 2006: 318). Los hallazgos de Calle Real 210-212 ejemplificarían por tanto una nueva "parcela", situada en la zona central de la antigua Antipolis estraboniana, en la que se habrían situado uno o varios talleres alfareros sucesivos desde la fase púnica inicial hasta quizá los inicios del dominio romano. Futu- ras intervenciones en los solares colindantes deberán precisar y ampliar las apreciaciones tipológicas y cronológicas propuestas en estas páginas, documentando con más generosidad los restos de las fases alfareras más antiguas y aportando un mayor número de estructuras, tal y como ha sucedido en los últimos años en el área de Villa Maruja - Janer (excavaciones inéditas de 2014-2015, anexas a las practicadas en 2002-2003).

\section{Agradecimientos}

Este trabajo es resultado de los proyectos de investigación ERGASTERIA. Arqueología experimental y virtual para el estudio de los procesos de producción anfórica y comercialización en la Protohistoria (Proyectos I+D+i FEDER Andalucía 2014-2020, Consejería de Economía y Conocimiento de la Junta de Andalucía; Ref. US-1266376) y GREPURE. Grecia Púnica Redescubierta (impulsado y financiado por la Fundación BBVA y la Sociedad Española de Estudios Clásicos, Programa Logos 2019, Ref. US-2020/1029).

\section{Bibliografía}

BERNAL CASASOLA, Darío; DÍAZ ROFRÍGUEZ, José Juan; EXPÓSITO ÁLVAREZ, José A.; SÁEZ ROMERO, Antonio M.; LORENZO MARTÍNEZ, Lourdes. 2004: "Los hornos de praefurnium escalonado (ss. III-II a.C.). Reflexiones a raíz del alfar de La Milagrosa (San Fernando, Cádiz)". En D. BERNAL y L. LAGÓSTENA (eds.): Congreso Internacional Figlinae Baeticae 2003. Talleres Alfareros y producciones cerámicas en la Bética romana (ss. II a.C. - VII d.C.), vol. II, pp. 607-620. BAR International Series 1266. Archaeopress. Oxford.

BERNAL CASASOLA, Darío; DÍAZ RODRÍGUEZ, José Juan; EXPÓSITO ÁLVAREZ, José A.; SÁEZ ROMERO, Antonio M.; LORENZO MARTÍNEZ, Lourdes; SÁEZ ESPLIGARES, Antonio. 2003: Arqueología y Urbanismo. Avance de los hallazgos de época púnica y romana en las obras de la carretera de Camposoto (San Fernando, Cádiz). Ayuntamiento de San Fernando. Jerez de la Frontera.

BERNAL CASASOLA, Darío; GARCÍA VARGAS, Enrique; SÁEZ ROMERO, Antonio M. 2013: “Ánforas itálicas en la Hispania meridional". En G. OLCESE, (ed.): Immensa Aequora. Ricerche archeologiche, archeometriche e informatiche 
per la ricostruzione dell'economia e dei commerci nel bacino occidentale del Mediterraneo (metà IV sec. a.C.-I sec. a.C.), pp. 351-372. Edizioni Quasar. Roma.

BERNAL CASASOLA, Darío; SÁEZ ESPLIGARES, Antonio; SÁEZ ROMERO, Antonio M.; DÍAZ RODRÍGUEZ, José Juan; LORENZO, MARTÍNEZ, Lourdes; TOLEDO COELLO, Francisco J. 2005: La Carta Arqueológica de San Fernando (Cádiz). Junta de Andalucía. Sevilla.

BERNAL CASASOLA, Darío; SÁEZ ROMERO, Antonio M.; BUSTAMANTE ÁLVAREZ, Macarena. 2011: "Entre la pesca y la púrpura en el Gadir tardopúnico. Actuación arqueológica en el conchero de la C/ Luis Milena de San Fernando". En C. ALFARO (ed.): Purpureae Vestes III. Textiles and Dyes in Ancient Mediterranean World, pp. 157-180. Universidad de Valencia. Valencia.

CINTAS, Pierre. 1950: Céramique Punique. Publications de l'Institut des Hautes Etudes de Tunis, III. Túnez.

CLAVAÍN GONZÁLEZ, Irene.; SÁEZ ROMERO, Antonio M. 2003: "La intervención arqueológica de urgencia en el Residencial David Fase II (UE 55) de El Pedroso (San Fernando, Cádiz)". Anuario Arqueológico de Andalucía/2000. Tomo III, pp. 174-182. Consejería de Cultura y Medio Ambiente de la Junta de Andalucía. Dirección General de Bienes Culturales. Sevilla.

CUOMO DI CAPRIO, Ninina. 1978: "Commento tecnico sulle fornaci del cosiddetto «Luogo di Arsione» di Mozia". En A. CIASCA (ed.): Mozia IX. Rapporto preliminare delle campagne di scavi 1972-1974, pp. 111-117. Università di Roma La Sapienza. Roma.

FALSONE, Gioacchino. 1981: Struttura e origine orientale dei forni da vasaio di Mozia. Studi Monografici I. Fondazione G. Whitaker. Palermo.

GARCÍA VARGAS, Enrique; SÁEZ ROMERO, Antonio M. 2018: "Todo el pescado vendido. Una lectura cuantitativa de la producción púnica y romana de ánforas, sal y salazones en la Bahía de Cádiz". En J. REMESAL, V. REVILLA, y J. M. BERMÚDEZ, (eds.): Cuantificar las economías antiguas. Problemas y métodos, pp. 161-214. Universidad de Barcelona. Barcelona.

GONZÁLEZ TORAYA, Beatriz; TORRES QUIRÓS, José; LAGÓSTENA BARRIOS, Lázaro; PRIETO REINA, O. 2001: "Los inicios de la producción anfórica en la bahía gaditana en época repu- blicana: la intervención de urgencia en Avda. Pery Junquera (San Fernando, Cádiz)". Congreso Internacional Ex Baetica Amphorae, I, pp. 175-186. Editorial Gráficas Sol, Sevilla-Écija.

LAVADO FLORIDO, María Luisa. 2017: “Control arqueológico de los movimientos de tierra en el proyecto de construcción tren-tranvía entre Chiclana de la Frontera y San Fernando. Tramo II: Caño Zurraque-San Fernando". Anuario Arqueológico de Andalucía/2008, pp. 690-706. Consejería de Cultura y Medio Ambiente de la Junta de Andalucía. Dirección General de Bienes Culturales. Sevilla.

LAVADO FLORIDO, María Luisa; SÁEZ ROMERO, Antonio M. 2009: "Un nueva área alfarera de Gadir". Boletín Ex Officina Hispana, 1, pp. 1213.

MUÑOZ VICENTE, Ángel. 1987: "Avance sobre el estudio de los ungüentarios helenísticos de Cádiz. 1986". Anuario Arqueológico de Andalucía/1986. Tomo II, pp. 520-525. Consejería de Cultura y Medio Ambiente de la Junta de Andalucía. Dirección General de Bienes Culturales. Sevilla.

MUÑOZ VICENTE, Ángel; DE FRUTOS REYES, Gregorio. 2006: "El complejo alfarero de Torre Alta en San Fernando (Cádiz). Campaña de excavaciones de 1988. Una aportación al estudio de la industria pesquera en la Bahía de Cádiz en época tardopúnica". I Conferencia Internacional Historia de la Pesca en el ámbito del Estrecho, vol. II, pp. 705-803. Junta de Andalucía. Sevilla.

NIVEAU DE VILLEDARY, Ana M. 2002: "Las ánforas turdetanas del tipo Pellicer-D. Ensayo de clasificación". Spal, 11, pp. 233-252.

NIVEAU DE VILLEDARY, Ana M. 2009: Ofrendas, banquetes y libaciones. El ritual funerario en la necrópolis púnica de Cádiz. Spal Monografías XII. Universidad de Sevilla. Sevilla.

NIVEAU DE VILLEDARY, Ana M.; SÁEZ ROMERO, Antonio M. 2016: "The red slip tableware of Punic and Early Roman Gadir/Gades (4th-1st c. BC): An updated assessment of the so-called Kuass Ware". En S. JAPP y P. KÖGLER, (eds.): Traditions and Innovations: Tracking the development of pottery from the Late Classical to the Early Imperial periods. IARPotHP First International Conference, pp. 55-68. Phoibos Verlag. Viena.

RAMON TORRES, Joan; SÁEZ ESPLIGARES, Antonio; SÁEZ ROMERO, Antonio M.; MUÑOZ 
VICENTE, Ángel. 2007: El taller alfarero tardoarcaico de Camposoto. Junta de Andalucía. Sevilla.

RUIZ MATA, Diego; PÉREZ PÉREZ, Carmen J. 1995: El poblado fenicio del Castillo de Doña Blanca (El Puerto de Santa María, Cádiz). Biblioteca de Temas Portuenses 5. Ayuntamiento de El Puerto de Santa María. El Puerto de Santa María.

RUIZ MATA, Diego; RUIZ GIL, José Antonio; LÓPEZ AMADOR, Juan José. 2006: “La pesca en época prerromana en la Bahía de Cádiz (Apéndice sobre las factorías de salazones en El Puerto de Santa María)". I Conferencia Internacional Historia de la Pesca en el ámbito del Estrecho, vol. I, pp. 269-338. Junta de Andalucía.Sevilla. SÁEZ ROMERO, Antonio M. 2008a: "El sistema alfarero-salazonero de Gadir/Gades. Notas sobre sus procesos de transformación y adaptación en época helenística". SAGVNTVM, 40, pp. 141-159.

SÁEZ ROMERO, Antonio M. 2008b: La producción cerámica en Gadir en época tardopúnica (siglos -III/-I). British Archaeological Reports International Series 1812. John \& Erika Hodges Ltd. Oxford.

SÁEZ ROMERO, Antonio M. 2013: “Talleres cerámicos en Gadir en época postcolonial ¿un modelo alfarero excepcional?". En D. BERNAL, L.C. JUAN, M. BUSTAMANTE, J.J. DÍAZ y A. SÁEZ, (eds.): Hornos, talleres y focos de producción alfarera en Hispania. Tomo I, pp. 215-249. La Ergástula. Madrid.

SÁEZ ROMERO, Antonio M. 2014: Alfares y saladeros de Gadir. Una aproximación arqueológica a la economía conservera de la Bahía de Cádiz en época púnica y tardopúnica (siglos -VI a -I). Tesis doctoral. Universidad de Cádiz. Cádiz.

SÁEZ ROMERO, Antonio M. 2018: "Pucheros y fogones. Aproximación a la evolución de la producción de «cerámicas de cocina» púnicas y tardopúnicas en Gadir". Ophiussa. Revista do Centro de Arqueologia da Universidade de Lisboa, 2, pp. 137-165.

SÁEZ ROMERO, Antonio M. 2019: “'Tipologías mediterráneas vs. tipologías locales? Valoraciones metodológicas a partir de una nueva propuesta de sistematización de la producción anfórica gaditana". Ex Officina Hispana Cuadernos de la SECAH, 3, pp. 39-80.

SÁEZ ROMERO, Antonio M.; BELIZÓN ARAGÓN, Ricardo. 2018: "Nuevos datos de los talleres cerámicos insulares de la Gadir púnica. Resultados preliminares de recientes excavaciones en el entorno de Villa Maruja - Polígono Janer (San Fernando, Cádiz)". Folia Phoenicia, 2, pp. 435-445.

SÁEZ ROMERO, Antonio M.; BERNAL CASASOLA, Darío; MONTERO FERNÁNDEZ, Ana I. 2014: "Las últimas ánforas púnico-gaditanas (ss. II-I a.C.). Precisiones tipo-cronológicas y estado de la cuestión". En A. M. ARRUDA, (ed.): $F e$ nícios e Púnicos, por Terra e Mar. Actas del VI Congreso Internacional de Estudios Fenicios y Púnicos, vol. II, pp. 866-878. Universidade de Lisboa. Lisboa.

SÁEZ ROMERO, Antonio M.; DÍAZ RODRÍGUEZ, José Juan. 2007: "La producción de ánforas de tipo griego y grecoitálico en Gadir y el área del Estrecho. Cuestiones tipológicas y de contenido". Zephyrus, LX, pp. 195-208.

SÁEZ ROMERO, Antonio M.; FERRER ALBELDA, Eduardo. 2019: "Dioses de barro. Sellos con simbología religiosa de la producción anfórica de Gadir (siglos IV-II a.C.)". En A.D. NAVARRO y E. FERRER (coords.): Trabajo Sagrado. Producción y representación en el Mediterráneo Occidental durante el I milenio a.C. Spal Monografías XXV, pp. 271-307. Universidad de Sevilla. Sevilla.

SÁEZ ROMERO, Antonio M.; GARCÍA VARGAS, Enrique. 2019: "La producción y comercio de ánforas y conservas de pescado en la Bahía de Cádiz en época fenicio-púnica. Nuevos datos, métodos y enfoques para viejos debates". En A. ÁLVAREZ, A. ÁLVAREZ-OSSORIO, G. BERNARD y V.A. TORRES-GONZÁLEZ (eds.): Fretum Hispanicum. Nuevas perspectivas sobre el Estrecho de Gibraltar durante la Antigüedad, pp. 23-71. Universidad de Sevilla. Sevilla.

SÁEZ ROMERO, Antonio M.; GUTIÉRREZ LÓPEZ, José M.; REINOSO DEL RÍO, M. Cristina. 2020: "Un asentamiento de época púnica en la campiña costera de la Bahía de Cádiz. Estructuras, fases de uso y contextos materiales de Puerto-19". Archivo Español de Arqueología, 93, pp. 61-80.

SÁEZ ROMERO, Antonio M.; LAVADO FLORIDO, M. Luisa. 2019: "Cremaciones fenicias y un nuevo saladero de pescado púnico de Gadir. Avance de los hallazgos registrados en el área de Los Chinchorros (Calle San Bartolomé, Cádiz)". Habis, 50, pp. 49-81.

SÁEZ ROMERO, Antonio M.; LUACES, Max; MORE- 
NO PULIDO, Elena. 2016: "Late Punic or Early Roman? A 2nd Century BC deposit from Gadir/Gades (Cadiz Bay, Spain)". Herom - Journal on Hellenistic and Roman Material Culture, 5 (1), pp. 27-77.

SÁEZ ROMERO, Antonio M.; MORENO PULIDO, Elena. 2017: "Contando la historia. Experiencias de cuantificación y análisis volumétrico en centros artesanales púnicos de la Bahía de Cádiz". Archivo Español de Arqueología, 90, pp. 219-246. 